\title{
Analysis of red chalk drawings from the workshop of Giovanni Battista Piranesi using fiber optics reflectance spectroscopy
}

\author{
Maria Krämer ${ }^{1,2^{*}} \mathbb{D}$, Ute Henniges ${ }^{1} \mathbb{D}$, Irene Brückle ${ }^{1} \mathbb{0}$, Laura Lenfant ${ }^{3}$ and Kirsten Drüppel ${ }^{3}$
}

\begin{abstract}
The viability of fiber optics reflectance spectroscopy (FORS) for the differentiation of red chalk drawing media was investigated, focusing on the group of drawings from the workshop of Giovanni Battista Piranesi (1720-1778) at the Staatliche Kunsthalle Karlsruhe, Germany. The evaluation of spectra was supported by principal component analysis (PCA). The method was tested on mock-up drawings made with recently acquired natural and synthetic red chalks of known origin. It was possible to sort these mock-up drawings according to chalk type and application technique. The compositional differences of these reference chalks were confirmed by X-ray diffraction (XRD) and scanning electron microscopy (SEM). Subsequent FORS analysis of selected original drawings revealed the existence of several closely grouped clusters, implying similarities on the basis of the underlying spectral features among the historical red chalks used in Rome. These similarities distinguished the historical drawings from the red chalk mock-up drawings, except for the drawings made with red chalk samples from the area near the town of Theley, Germany, which were shown to bear close similarities to those in the cluster of historical samples.
\end{abstract}

Keywords: Fiber optics reflectance spectroscopy, X-ray diffraction, Scanning electron microscopy, Giovanni Battista Piranesi, Multivariate statistics, Principal component analysis, Reflectance spectra, Red chalk, Drawing

\section{Introduction}

In this study, we examine the viability of fiber optics reflectance spectroscopy (FORS) as a method for differentiating red chalk drawing media on paper. Our work was carried out in the context of a research project funded by the German Research Foundation (DFG), in which three international partners are studying a group of about 300 drawings at the Staatliche Kunsthalle Karlsruhe (see Funding and Acknowledgements). These drawings have been reattributed to the Roman workshop of the Italian architect, etcher, and dealer in antiquities Giovanni Battista Piranesi (1720-1778) in 2014 [1-3]. Among the drawings are many that were executed in natural red chalk. Since this was one of the most

\footnotetext{
*Correspondence: kraemer.papierrestaurierung@googlemail.com ${ }^{1}$ Stuttgart State Academy of Art and Design, Stuttgart, Germany Full list of author information is available at the end of the article
}

versatile drawing mediums used by 18th-century artists, draftsmen, and etchers alike ([4] p 128, $[5,6])$, it is not surprising that it was favored by Piranesi and his circle. Red chalk has a high and varied color intensity and is exceptionally useful in the etcher's workshop for copying and transferring drawings mechanically or via counterproofing. It was a medium for masters in particular, since the tendency of its fine particles to adhere to the fibers of the paper surface ([5], p 110) precluded erasure and correction.

The Karlsruhe drawings illustrate the rich variety of red chalk tonalities (Fig. 1), ranging from the bright orange prevailing in many 16th-century drawings to the dark reddish tones of the eighteenth century, found especially in French drawings, as already identified by Meder in 1919 ([4] p 121). In the Piranesi workshop, where several different draftsmen were employed and closely cooperated, this wide range of red-chalk tonalities appears in a
Springer Open

(c) The Author(s) 2021. Open Access This article is licensed under a Creative Commons Attribution 4.0 International License, which permits use, sharing, adaptation, distribution and reproduction in any medium or format, as long as you give appropriate credit to the original author(s) and the source, provide a link to the Creative Commons licence, and indicate if changes were made. The images or other third party material in this article are included in the article's Creative Commons licence, unless indicated otherwise in a credit line to the material. If material is not included in the article's Creative Commons licence and your intended use is not permitted by statutory regulation or exceeds the permitted use, you will need to obtain permission directly from the copyright holder. To view a copy of this licence, visit http://creativecommons.org/licenses/by/4.0/. The Creative Commons Public Domain Dedication waiver (http://creativeco mmons.org/publicdomain/zero/1.0/) applies to the data made available in this article, unless otherwise stated in a credit line to the data. 

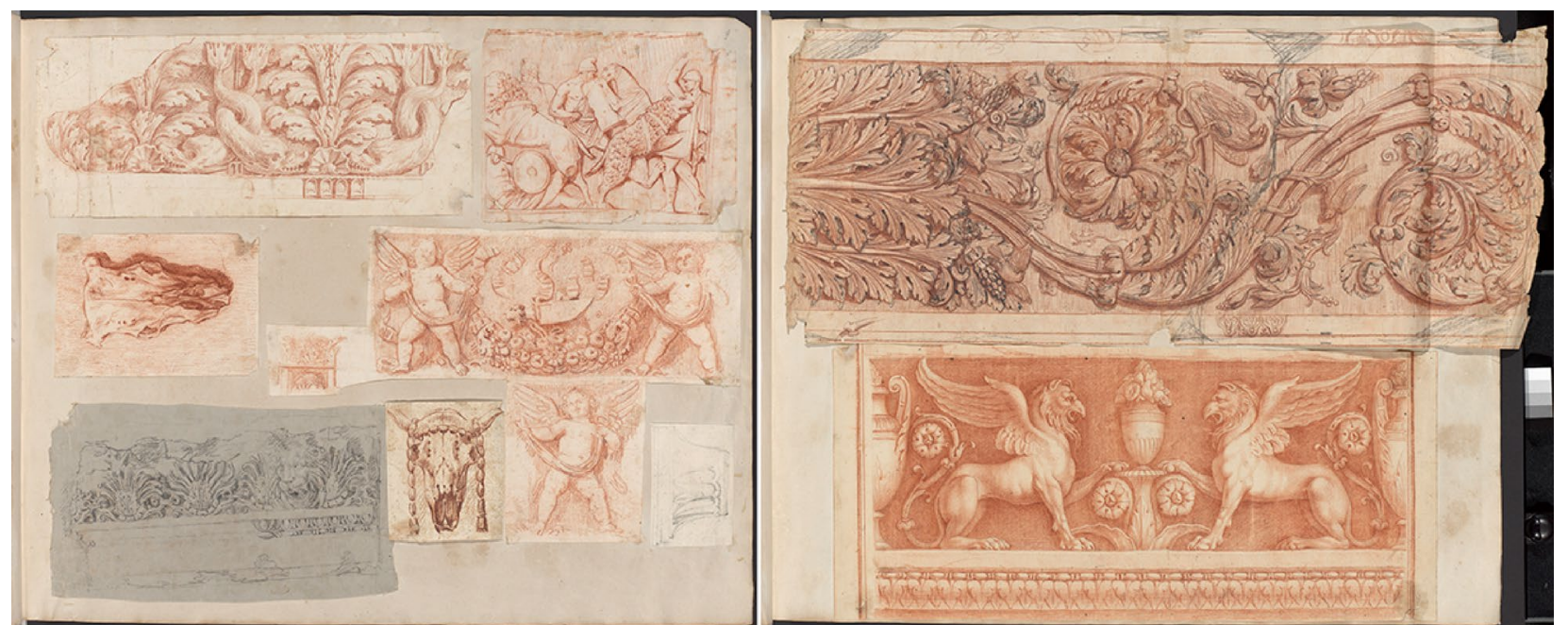

Fig. 1 Two leaves of the Karlsruhe Albums, showing a selection of the red chalk drawings (Staatliche Kunsthalle Karlsruhe, folios 9 (left) and 10 (right) of Volume 1, Inv.-No. IX 5159-35); photographs: Annette T. Keller

narrowly defined chronological and geographical context. This makes the drawings an ideal group for the study of variations in color, especially since they were kept undisturbed in albums since the early nineteenth century. Of special interest in FORS analysis are color variations that result from the compositional differences of the chalks and the additional color variations that result from the artists' application techniques. Smudging, whether intentionally performed, or due to wear, lightens the color; a darker color and a smoother line are produced as a result of contact with oiled paper when tracing a design, or by the moistening and pressing of a drawing during counterproofing, as has been shown in a study of the 18th-century artist Daniel Chodowiecki (1726-1801) [7]. These variations are visually differentiable, and can be photographically documented, but those methods are insufficient for the systematic color-oriented comparison of a large number of drawings in numerous collections located far apart from each other. FORS presents an interesting option because it allows rapid measurements, is portable, in our setup was contact-free, and could be used for the comparison of the Karlsruhe drawings with authenticated drawings by Piranesi in other collections.

\section{Factors influencing color variation in red chalk}

Geologically, natural red chalk can be classified as a type of ocher ([5] p 99). The hue and intensity of its color result from its mineralogical composition, especially its contents of iron oxides and hydroxides. Reddish ochers primarily contain hematite, $\mathrm{Fe}_{2} \mathrm{O}_{3}$, whereas goethite, $\alpha-\mathrm{FeOOH}$, is the main Fe-bearing phase in yellowish ochers ([8] p 70). The total amount of non-tinting components, such as kaolinite, illite, calcite, gypsum, and dolomite have influence on the lightness of ochers [8]. Natural red chalk from a single mineral deposit can exhibit varying hues and intensities ([9] p 29), thus artists had a range of tonalities to choose from, even before the advent of fabricated and synthetic chalks. Red chalk sticks available in stores today are made by adding a binder to a homogenized pigment-filler mixture and pressing the paste into forms. Mayer and Vandiver refer to all of these man-made chalk sticks as fabricated chalks and speak of synthetic chalks, when they contain hematite that does not stem from natural sources, but is artificially produced [10].

Morphological differences, including grain size and shape of the Fe oxide and hydroxide crystals, along with their density and presence of impurities in the form of other metal ions, also influence their color appearance. For synthetically produced hematite, it has been shown that particle shape and size influence reflection properties: Acicular particles reflect light at higher VIS wavelength ranges more intensively than isometric ones ([11]; depicted in [12] p 135, Fig. 6.12). Furthermore, the hue of hematite changes from yellowish-red to red-purple as the particle size increases from $0.1 \mu \mathrm{m}$ to $1.0 \mu \mathrm{m}$ ([13] p 57, Fig. 4-1), on to a purplish hue for particle sizes of $\sim 1.5 \mu \mathrm{m}$ ([14] p 183-184).

Natural red chalk has been found to contain hematite platelets, while synthetic red chalk made from artificial hematite features roundish particles; thus a stronger dependency between particle orientation and color is seen in natural red chalk ([10], p 176). This dependency became apparent when field-emission scanning electron 
microscopy (FESEM) was used to study the effects of red chalk drawing techniques on paper ([5] p 110). Wet application resulted in a thick, clumped-up deposit on the paper; dry smudging caused small particles to distribute thinly across the paper surface, with small, iron-rich particles directly attached to the cellulose fibers. Historical sources also indicate that the color of a natural red chalk was manipulated by heating or acid treatment, with varying degrees of success ([15] p 84, [16] p 205).

\section{Analyses of red chalk and red ocher}

Mayer and Vandiver ([10] p 174, p 432) studied hematite and red ocher samples from the Forbes Collection of pigment material, as well as red Conte crayons, using X-ray diffraction (XRD) and scanning electron microscopy (SEM). The samples were composed of $50-80 \%$ hematite and $20-50 \%$ clay, and varying amounts of quartz. Mayhew et al. analyzed five natural red chalks from different geological sites (in Arizona, Burgundy in France, and three regions in Germany, see Additional file 1: Table S1) using XRD to study their different mineralogical compositions ([5] p 101-103). In two of the five samples no hematite could be detected. The authors suggested this could be due to the small size of the hematite particles present, or to their low crystallinity. FESEM revealed natural red chalk strokes on paper to be composed of larger secondary plate-like silicate particles covered by smaller, iron-containing particles, presumably hematite ([5] p105-106). Mößbauer spectroscopy was used to quantify iron-bearing minerals (goethite, hematite, and clay minerals) in ochers from Roussillon, France [17]. Hematite concentrations of $1.5-43.2 \%$ were detected in eight of the nine samples. Colored iron compounds in ocher have also been classified using the Munsell Color Charts [18], which are easy to use in field work, and colorimetric methods based on the CIELAB system established by the International Commission on Illumination (commonly known by its French acronym, CIE), a colorimetric system that reproduces human color perception. Both systems utilize data derived from visible (VIS) spectroscopy $[8,17-21]$.

In UV-VIS spectroscopy, absorption bands in the reflection or absorption spectrum provide information on the electron transitions taking place in the material. These bands are broad and overlap each other, but they can be amplified and better isolated by calculating derivatives of a spectrum [22]. The color of iron oxide pigments was shown to result from the crystal-field transitions of $\mathrm{Fe}(\mathrm{III})$ in an octahedral ligand field [23]. For hematite and goethite, the influence of the ligand-to-metal charge transfer is predominant. It takes place in the UV range, with its absorption edge extending into the VIS range ([8] $\mathrm{p}$ 76). The electron transfer $2\left({ }^{6} \mathrm{~A}_{1}\right) \rightarrow 2\left({ }^{4} \mathrm{~T}_{1}\right)$ is made possible by the specific shape of the crystal structure of hematite, in particular, by the face-sharing octahedra, which are not found in yellow iron hydroxides. This structural difference is responsible for the shift of the absorption bands toward higher wavelengths, and thus a color shift from yellow to red ([23] p 1268).

Elias et al. [8] were able to detect a correlation between the $\mathrm{a}^{*}$ (redness) coordinate of CIELAB and the position of the inflection point of the steep slope of the VIS reflectance spectrum of ocher samples. The higher the redness value $\mathrm{a}^{*}$ and the content of hematite found in the total amount of iron oxides were, the further the inflection point shifted toward the higher wavelengths. The inflection points differed depending on the hues of yellow, orange, and red ochers, with the red ocher accordingly at the highest wavelengths $(575-580 \mathrm{~nm})$.The non-tinting constituents of the ochers containing hematite as the main color-forming compound had little influence on the position of the inflection point, but influenced the lightness reading.

While earlier studies aimed at analyzing the physical properties of red chalk or understanding the connection between color and composition of ochers, in this study, we aim to explore the viability of FORS-derived spectra in combination with compositional analysis and principal component analysis (PCA) and better describe similarities and differences of modern and historic red chalk on paper. While FORS in itself is well established as an analytical method to help identify artists' materials [24-29], PCA was successfully used in the past to differentiate materials of similar composition, such as synthetic and natural ultramarine blue [30], black drawing media [31], and various kinds of marker pen inks [32] and thus seems promising for the differentiation of natural red chalks.

\section{Experimental methods and materials Analytical concept}

FORS was used on red chalk drawing mock-ups made with recently acquired natural red chalks (Table 1), and on selected original drawings. The reflectance spectra between 300 and $1000 \mathrm{~nm}$ were acquired by means of contact free measurements and used to characterize the coloring components of the red chalks. The FORS reflectance spectra were analyzed statistically via principal component analysis (PCA). PCA is a method in multivariate statistics and used to explore complex data sets by computing their principal components. Principal components can be used to detect, characterize, and visualize the variance of these data sets. The red chalks were also analyzed with XRD, a method used to qualify and quantify crystalline structures in a substrate. It was used to quantify their mineralogical composition, and thus, to support the interpretation of the FORS spectra. SEM was 
Table 1 Red chalk types ( $n=$ natural, $s=$ synthetic)

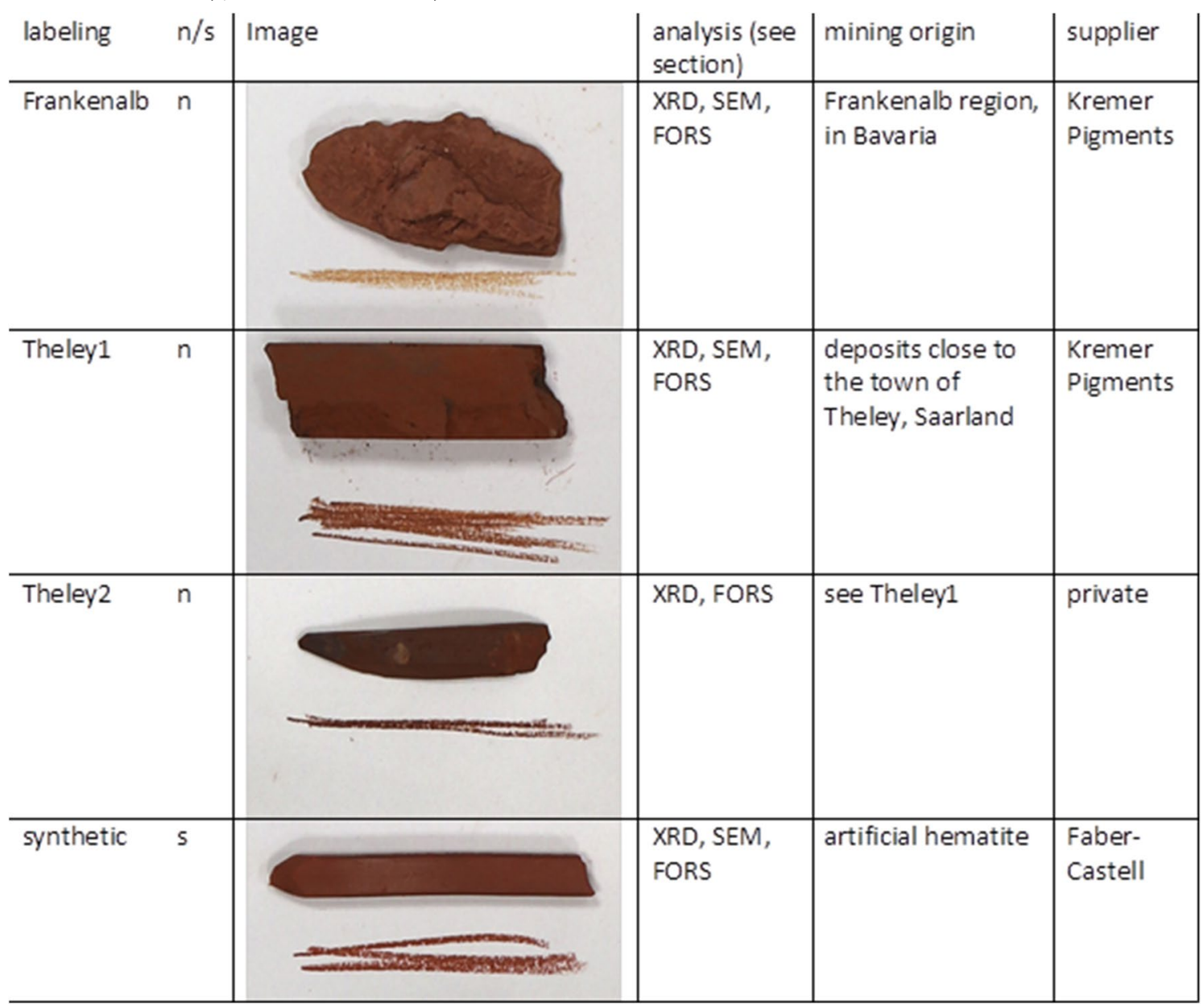

used to determine the elemental composition of the main phases, the distribution of particles in the chalk lines of drawings, and their topography.

\section{Red chalks studied}

Three natural and one synthetic red chalks were used (Table 1). Two types of natural chalks (from German deposits in the area around the town of Theley, Saarland, and the Frankenalb region in Bavaria) were purchased from Kremer Pigments. One additional red chalk sample from the Theley area (sample name "Theley2") was separately acquired from a private contact. The synthetic chalk used in our study was a Faber-Castell Pitt, No. 122823, made with artificial hematite. Several samples were taken from the chalk pieces for XRD, and FORS readings were taken at several locations on the drawing mock-ups.

\section{X-ray diffraction}

In order to determine the mineralogical composition of the red chalks, XRD was performed with a D8 Discover instrument (Bruker AXS GmbH), operated at a power setting of $40 \mathrm{kV}$. Each chalk sample was ground by hand, using an agate mortar. Powder XRD patterns were collected at ambient conditions in the $2 \Theta$ range from 2 to $82^{\circ}$, using a step size of $0.02^{\circ} / 2 \Theta$ and a counting time of 4 s per step. EVA software (Bruker AXS GmbH) was used for qualitative and semi-quantitative phase analysis.

\section{Scanning electron microscopy}

The Frankenalb, Theley1, and synthetic red chalks samples were analyzed, using a Tescan Vega 3 instrument. All samples were coated with a nanometer-thick carbon layer, using a Cressington Carbon Coater 108, to increase their electrical conductivity. The chalks' textures were examined in back-scattered electron (BE) mode with an 
acceleration voltage of $15 \mathrm{kV}$, mainly in order to identify hematite and rutile. Semi-quantitative analyses of the mineral compositions were conducted with energydispersive X-ray spectroscopy (EDX), using an OXFORD INCA $x$-act instrument, coupled with the SEM. The surface topography of chalk strokes on paper was analyzed mainly in the secondary electron (SE) mode.

\section{Red chalk drawing mock-up preparation}

Drawing mock-ups (Table 2) were prepared with red chalks applied on handmade gelatin-sized rag papers (from here on "historical paper, hp") and handmade gelatin-sized flax papers (acquired from Gangolf Ulbricht, Berlin; from here on "modern paper"). To simulate different artists' drawing techniques, the chalks were applied either dry, rubbed, wet or oiled (using olive oil; only on modern paper, excluding Theley2, due to effects overlapping with the wet application). On each mock-up, the chalk was applied in diminishing intensity from high to low coverage (left to right side), to study also the effect of white paper show-through. The chalk application techniques were chosen to simulate the greatest possible range of color variation of a particular red chalk. On aged red chalk drawings, it should be added that applicationrelated differences are most probably diminished, as even smudged chalk lines tend to be compacted and smoothened over time.

\section{FORS: data acquisition}

The reflectance spectra were measured using an OceanOptics $\mathrm{H} 2000$ + spectrometer with a detection range of 200-1100 nm (detector sensitivity 130 photons/count at $400 \mathrm{~nm} ; 60$ photons/count at $600 \mathrm{~nm}$ ). The light source (DH-2000-BAL) was equipped with a deuterium lamp and a tungsten halogen lamp. Two Zenith Polymer reflectance standards (99\% and $2.5 \%$ reflectance) were used to calibrate the measurements. The optical fiber heads were fixed in a custom-built frame that enabled contact-free $\mathrm{x}-\mathrm{y}-\mathrm{z}$ positioning at desired measuring locations. The measuring points (see Table 2) were illuminated from two sides at a $45^{\circ}$ angle; the measuring head was in the $0^{\circ}$ position. During the measurement process, the holder with the fiber heads was covered with a cardboard hood lined with black velvet to exclude ambient light. The integration time fluctuated due to small differences in the insertion of the fiber into the holder. It was adjusted by means of a reflectance standard to conform to $85 \%$ $(14,000$ counts) of the spectrometer's signal capacity before each measurement to improve the replicability of the measurements. The spectra captured were averaged from at least 20 singular spectra.

\section{FORS: CIELAB}

CIELAB color values were calculated from the unprocessed FORS spectra via $10^{\circ}$ standard observer, D65 illuminant, and at a resolution of $5 \mathrm{~nm}$.

\section{FORS: data pre-treatment and PCA}

Elias et al. [8] established a relationship between the redness of ochers and the position of the inflexion point of the steep slope in the shorter wavelengths of their VIS reflectance spectra by looking at the first derivative of each spectrum, where the inflexion point is transformed into a maximum. In reference to these findings, several sections of the spectra were analyzed with PCA. The clearest separation of the mock-up samples by chalk origin and type was achieved with the wavelength range of $500-650 \mathrm{~nm}$, where the reflection properties of red chalk were consistently measurable even in thin chalk layers.

The FORS spectra were processed and analyzed with the help of a software program (Unscrambler X, Data version 10.5.1; Camo Analytics). Spectra were smoothed, normalized, corrected for multiplicative scattering effects, and the first derivative was computed.

Due to the uneven substrate surface, the contact-free measurement setup, and the instrument's high level of spectral resolution ( $\Delta \lambda$ average $0.45 \mathrm{~nm}$ ), the spectra displayed multiplicative scattering effects and they were also noisy. The spectra were smoothed using the SavitzkyGolay algorithm [33] in the software (61 pts, polynomial order 0 ). The window adopted for smoothing was relatively large, but since the VIS spectra of red chalks feature broad bands, it was expected that smoothing would not result in the loss of key information.

Several normalization methods and corrections of the scattering effect were compared to each other to investigate their effectiveness and their possible effects on the PCA results. Mean normalization (the division of each spectrum by its average) followed by a multiplicative scattering correction (MSC) proofed to be the best pre-treatments to reduce variation caused by the noncontact measurement setup, as spectra of the same chalk and application technique showed best congruence after processing. The calculation of the derivative was carried out via the Savitzky-Golay algorithm (61 pts smoothing, second polynomial order). Paper show-through resulted in higher reflectance values at lower wavelength regions with a shortened rise (Fig. 2a). With the first derivative, 
Table 2 Red chalk drawing mock-ups

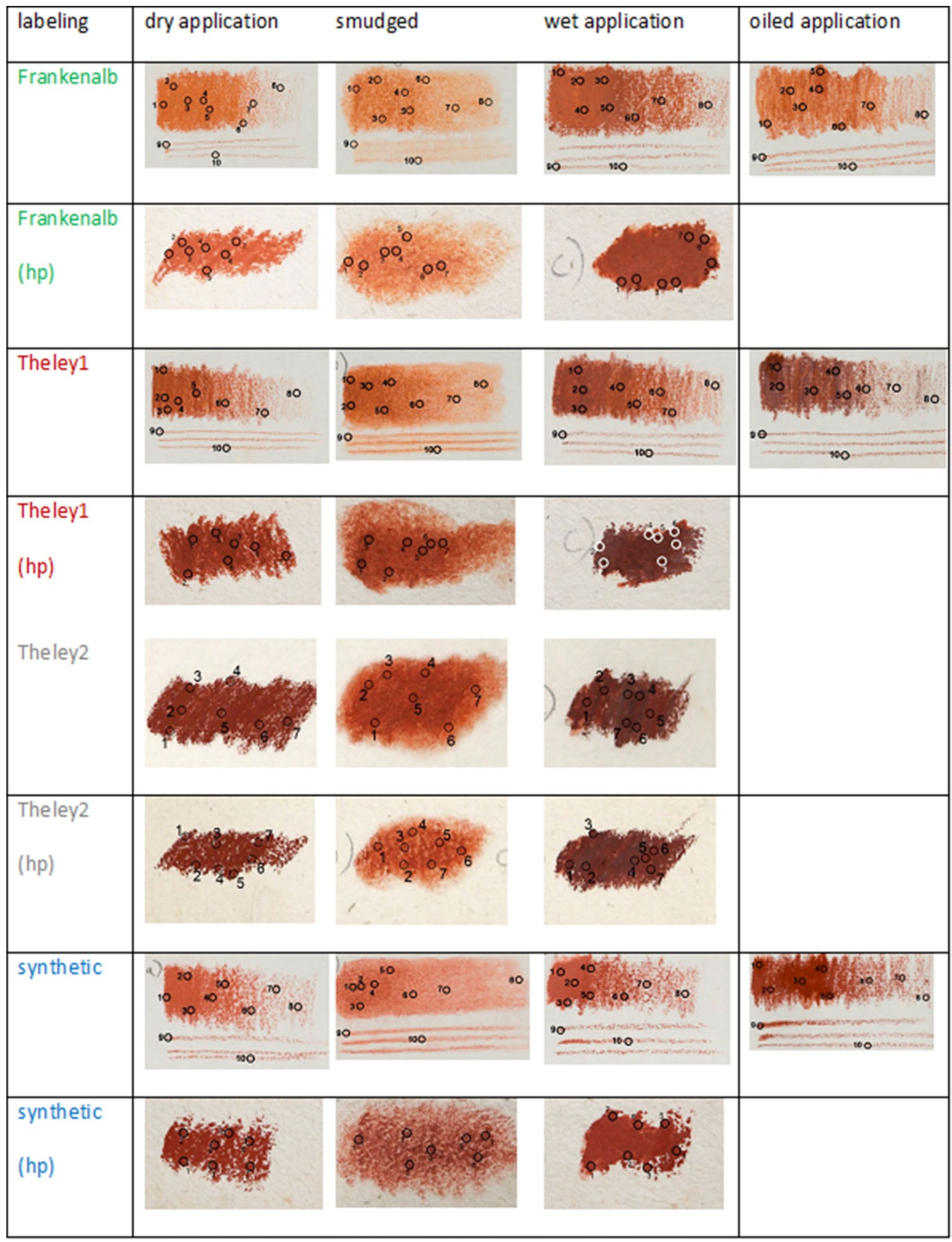

Circles indicate FORS measuring points. Images are not color-calibrated. $(\mathrm{hp})=$ historic paper 


$$
v_{i}
$$




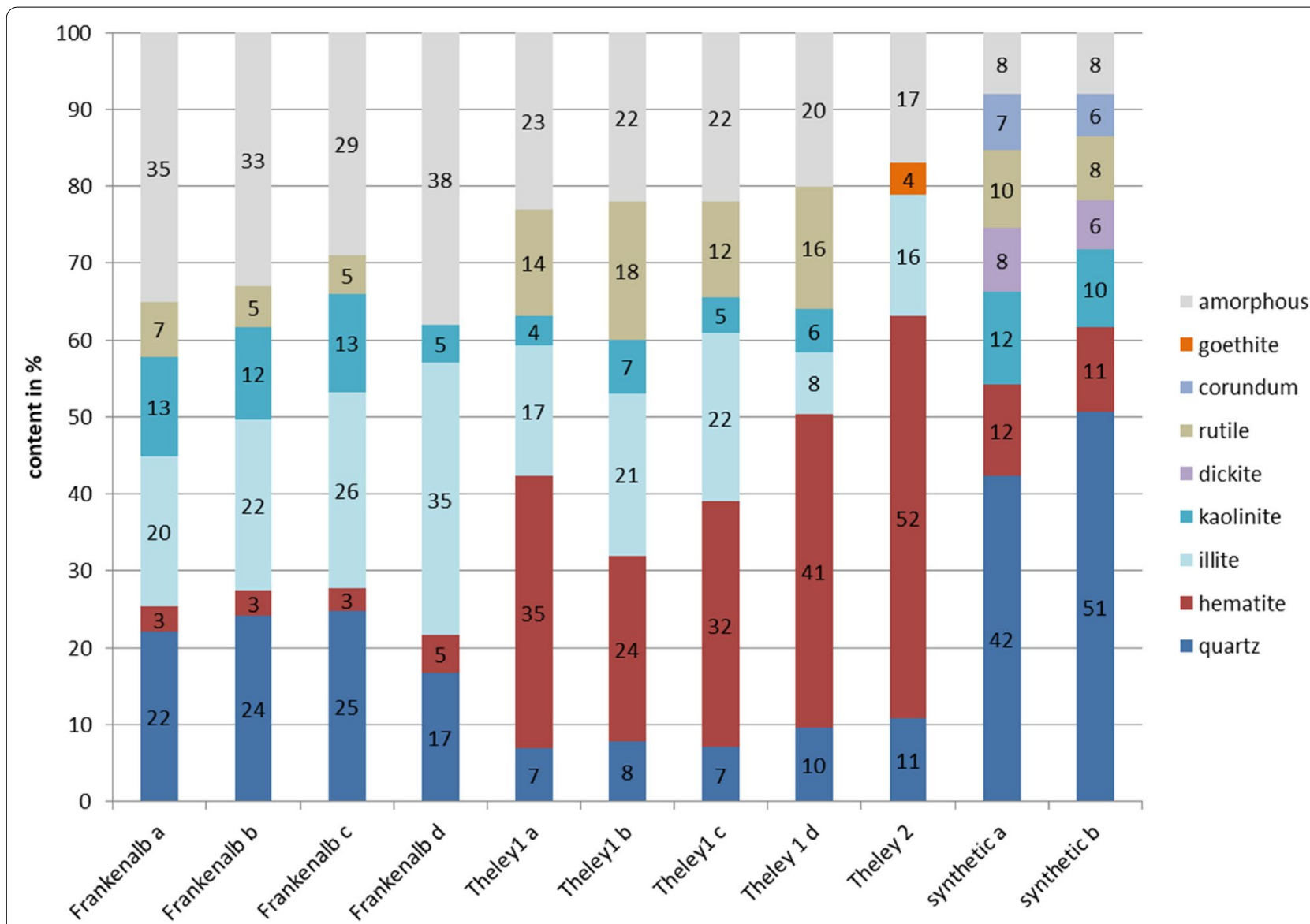

Fig. 3 Mineralogical composition of red chalks, determined via powder XRD. Letters (a, b, $c$, d) indicate multiple samples/readings of different batches of the same chalk type, samples acquired between 2000 and 2014

the spectra from the mix of paper and pigment in the range of 500-650 nm display a weakening and a shift of the maximum in the lower wavelengths (Fig. 2b). Because of this impact on the spectra, only the five measuring points for the most densely-applied strokes were used.

The spectra were further differentiated via PCA. There are various published models for PCA [34, 35]. For our PCA analysis, the singular value decomposition (SVD) for smaller data sets and nonlinear iterative partial least squares (NIPALS) algorithms for complex data sets were used as selected by the software; the validation method was full cross-validation and the data were mean-centered.

\section{Results and discussion}

\section{XRD: mineral modes of red chalks}

To investigate the variation in the mineral composition of the chalks from natural deposits (samples Frankenalb and Theley1), multiple samples acquired between
2014 and 2020 were measured with XRD (labeled a, b, c, etc.). All chalk samples are composed of varying proportions of quartz, clay minerals (illite, kaolinite, and/ or dickite), and hematite (Fig. 3; also Additional file 1: Fig. S2). Additional rutile, $\mathrm{TiO}_{2}$, is a minor phase in most analyzed samples. Remarkably, the Theley1 and 2 natural chalks contain significantly more hematite and less quartz than the Frankenalb and synthetic chalks. The Theley 2 sample additionally contains goethite, which presumably formed at the expense of former hematite during weatheringin a near-surface environment. The Frankenalb chalk tends to contain more quartz and clay minerals and significantly less hematite than samples from Theley. In the synthetic chalk, dickite and kaolinite are the dominant clay minerals whereas illite is absent. Quartz contents are remarkably high. The additional presence of corundum in the synthetic chalk is likely attributable to an abrasion of the grinding gear used during production of the chalk 

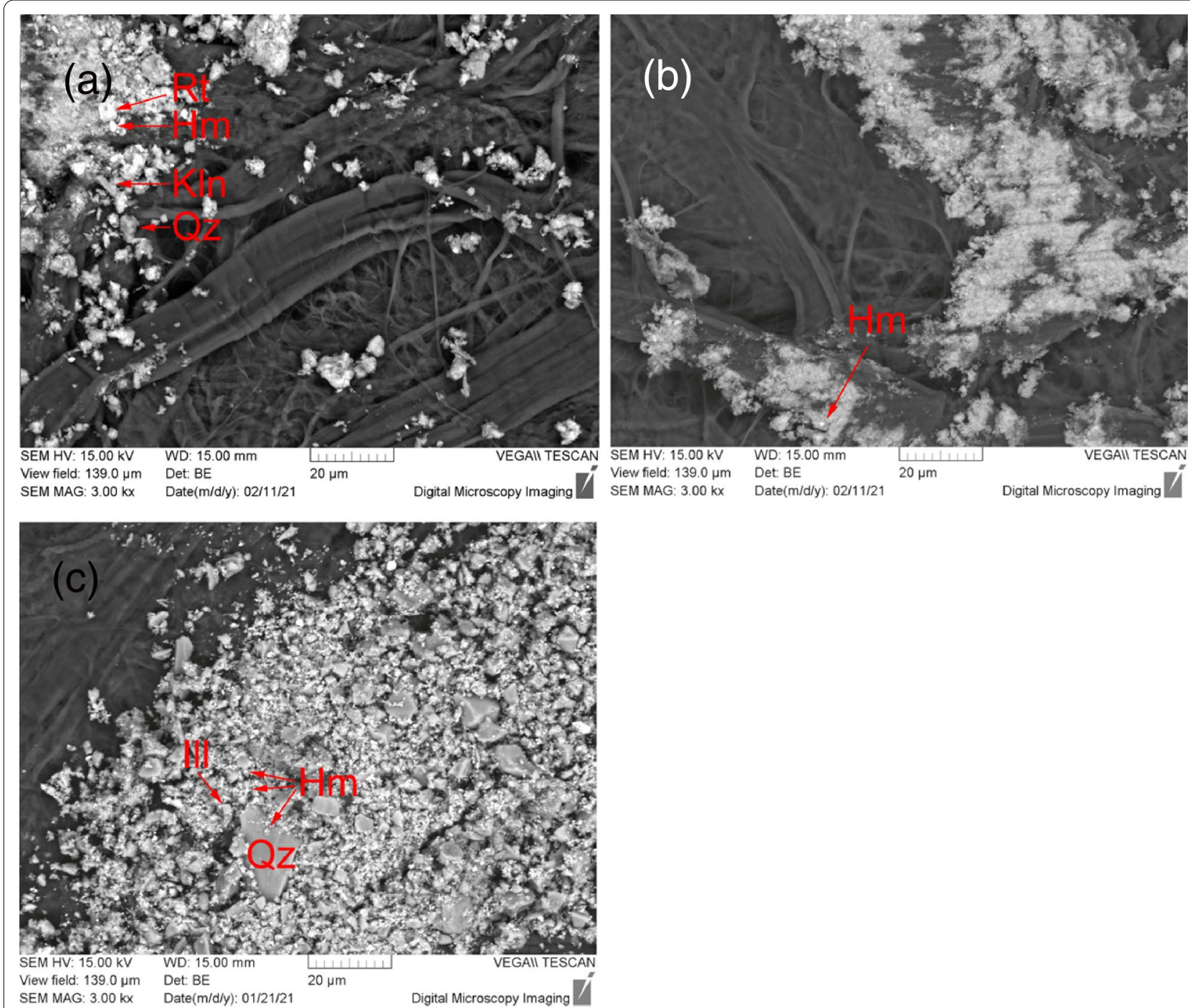

Fig. 4 a-c SEM images (BSE mode) of red chalk applied dry on paper: Frankenalb (a), Theley1 (b) and synthetic (c). The white particles consist mainly of hematite and minor rutile. The gray particles include illite, kaolinite, and quartz (Hm: hematite, III: illite, Kln: kaolinite, Qz: quartz, Rt: rutile)

sticks. The chalks also display differences with respect to the proportions of amorphous material; the lightestcolored chalk (Frankenalb), which has greater amounts of silicates, shows the highest contents of amorphous material, and the synthetic chalks the lowest. The variability in the mineral modes is generally higher in the natural than in synthetic chalk samples.

\section{SEM-EDX: mineral composition, textures, and topography of the chalks \\ Mineralogical composition}

The mineral phases of the three chalk types Frankenalb, Theley1, and synthetic, identified via SEM-EDX, correlate well with the XRD results (see 3.1). At high magnifications, it was possible to analyze individual mineral grains of quartz and illite. These minerals are present in variable but mostly high proportions. Grain sizes are mostly in the micrometer to sub-micrometer range. Minor phases are kaolinite and rutile (Fig. 4). Hematite is present as small platelets, with strongly variable grain sizes, ranging from sub-millimeter up to $5 \mu \mathrm{m}$.

For each phase, the grain size and amount vary strongly both within individual samples and among different samples. Frankenalb chalk exhibits grain sizes from $<1 \mu \mathrm{m}$ for the round hematite particles, up to $15 \mu \mathrm{m}$ for the flaky illite, and $10 \mu \mathrm{m}$ for the kaolinite (Fig. 4a). Theley1 featured only a few large grains (average $=1 \mu \mathrm{m}$ ); overall, it 

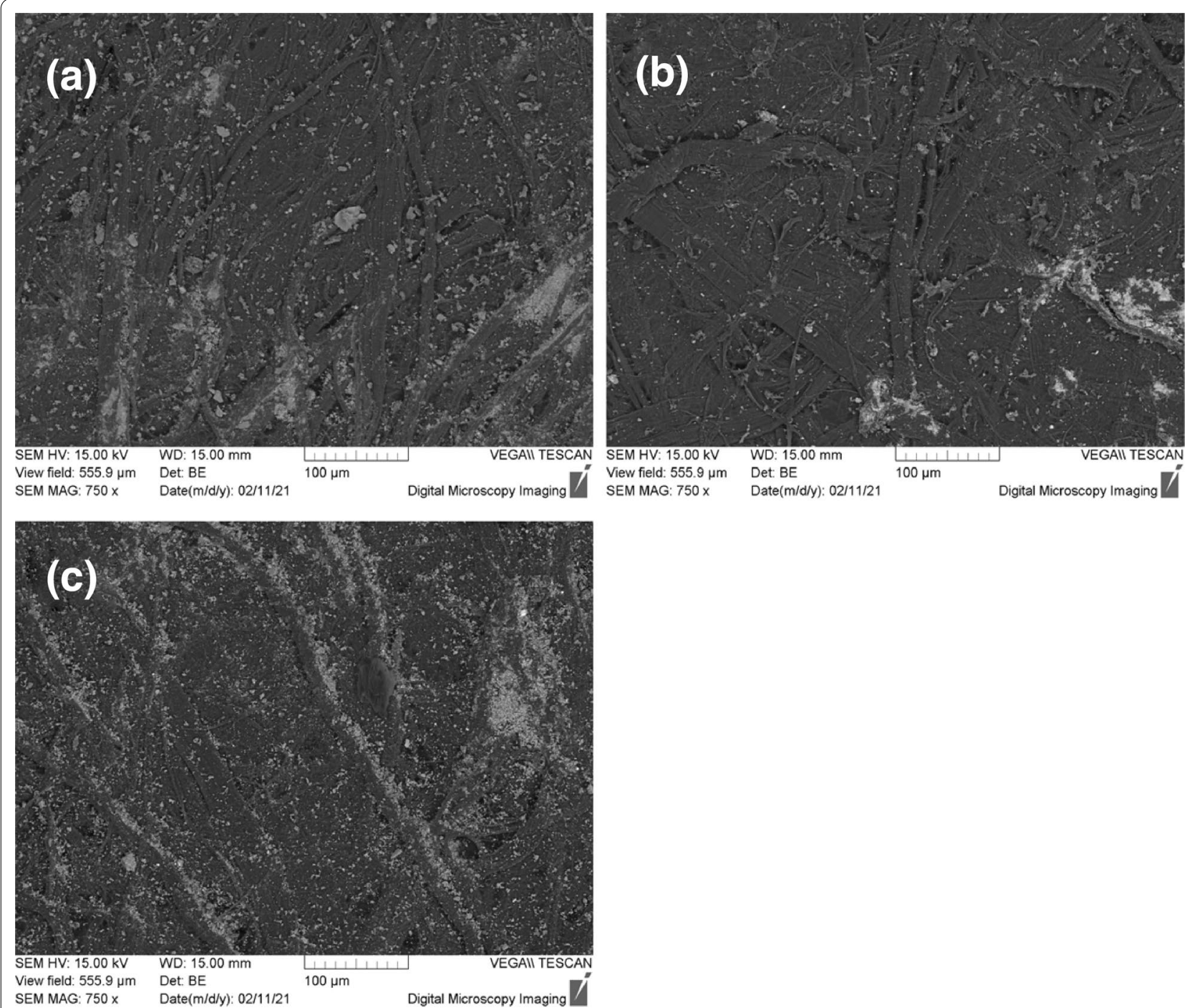

Fig. 5 a-c SEM images (BE mode) of smudged red chalk strokes on paper: Frankenalb (a), Theley1 (b), and synthetic (c). The chalk mineral grains are finely dispersed and scattered across the paper surface to various degrees, depending on grain size and shape: (b) finest grains with the least amount of scattering; (c) coarsest grains, largest amount of scattering, with particles accumulating in the valleys between fibers

consisted of small, uniform grains that contributed considerably to a closed, compact surface of the chalk stroke (Fig. 4b). In the synthetic chalk sample, angular quartz fragments exhibit a large grain size of up to $20 \mu \mathrm{m}$. The sub-rounded hematite and clay mineral particles, in contrast, are only about $0.5-2 \mu \mathrm{m}$ in size and homogenously distributed (Fig. 4c). It was not possible to detect an accumulation of hematite in any of the samples.

\section{Effect of smudging on chalk distribution}

In all of the red chalk strokes, the mineral particles accumulated along the papermaking fibers on the paper surface. The degree to which the particles were dispersed during smudging varies as a function of the grain form and size, an effect most easily discernible in the areas between the red-chalk strokes. The coarse-grained Frankenalb chalk shows some grains scattered between the chalk strokes, although most of the grains remain where they had been laid down (Fig. 5a). The fine-grained Theley1 shows only a few grains scattered by smudging (Fig. 5b), due to the greater adhesive forces between the small-sized particles. In comparison, the grains in the synthetic red chalk are scattered to the greatest degree (Fig. 5c). The variability of the grain sizes in the sample, 

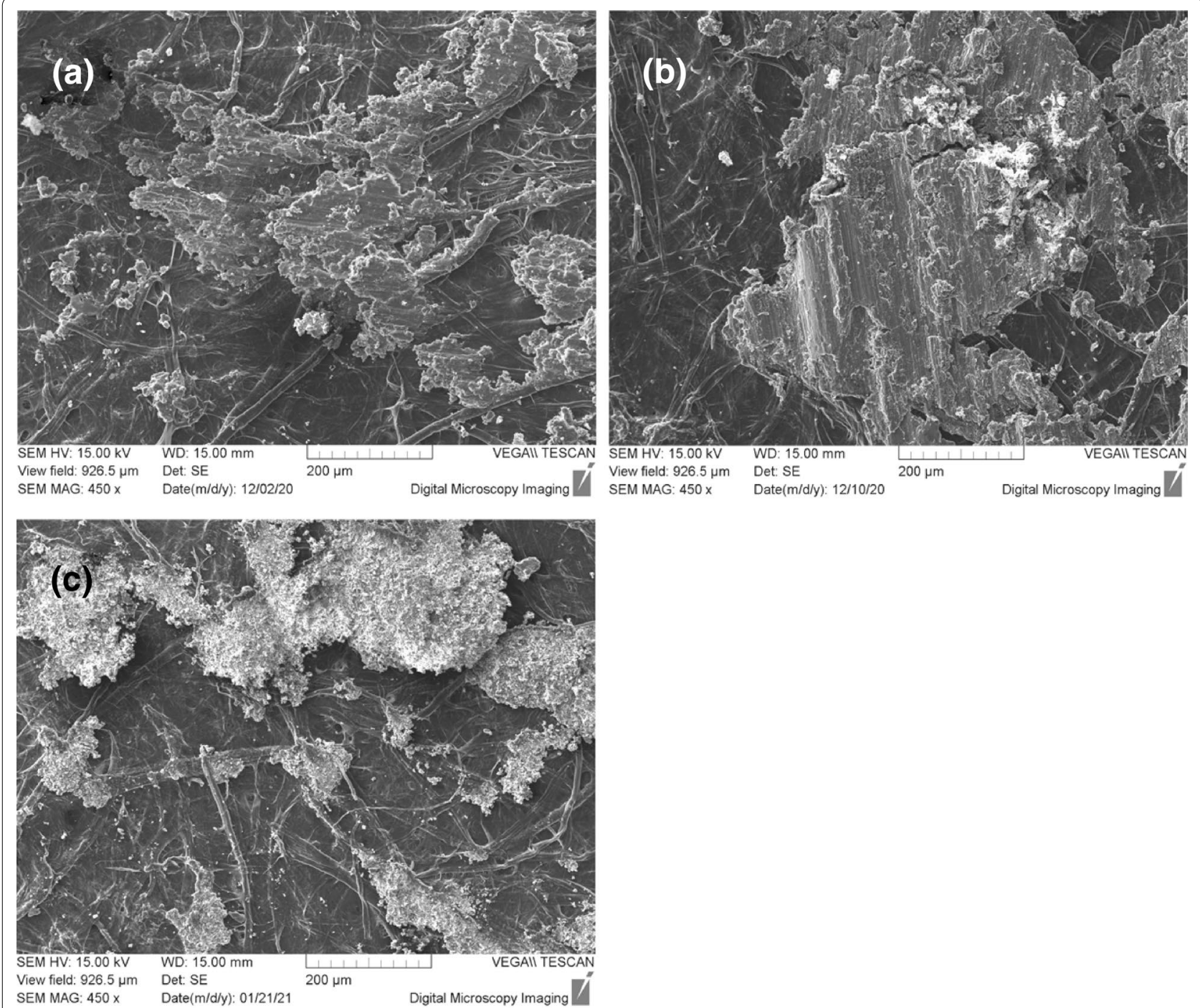

Fig. 6 a-c SEM images (SE mode) of red chalks applied wet on paper: Frankenalb (a), Theley1 (b), and synthetic (c). The chalk strokes form thick layers that coat the paper surface. Moisture-induced caking results in diminished surface roughness, which is observable to a greater extent in the natural chalks than the coarse-grained synthetic chalk

with particle sizes of up to $20 \mu \mathrm{m}$ in diameter, results in significantly lower adhesive forces among the grains.

\section{Effect of wet application on chalk topography}

It is evident from the SE images that the wet application method results in a change in the dispersion of the mineral grains. The application of the chalk strokes resulted in a more extensive abrasion of the chalk and therefore thicker coating of the paper. Chalk banks are not-in contrast to the chalk strokes in the dry applicationsoriented in the direction of the papermaking fibers. The surface of the chalk strokes of both natural samples,
Frankenalb and Theley, is relatively even and massive. A fragile topography is found only in the marginal areas of the chalk applications (Fig. 6a, b). In contrast, the wet application surface of the synthetic chalk is uneven and rough, probably due to the abundant coarse quartz particles (Fig. 6c). These different topographical features of the three red chalks will have a major impact on their lightness and color saturation. Smooth surfaces (e.g., wet chalk strokes) tend to appear darker because they show a greater amount of light reflection than rough (e.g., dry chalk strokes, synthetic chalk) surfaces that show a greater amount of light scattering [36]. 


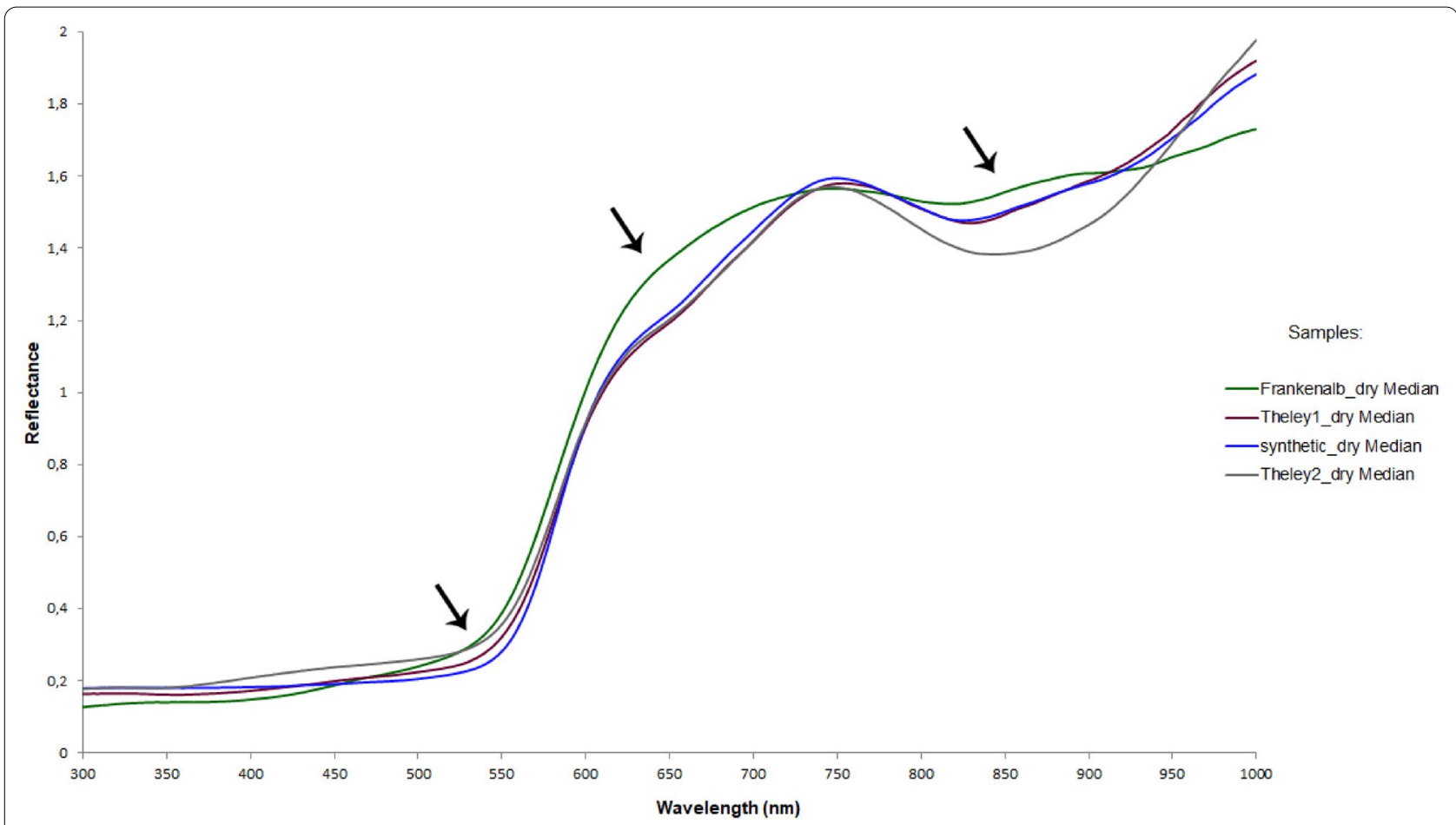

Fig. 7 Median FORS spectra for all chalk types applied dry on modern paper. Arrows mark areas with most significant variance
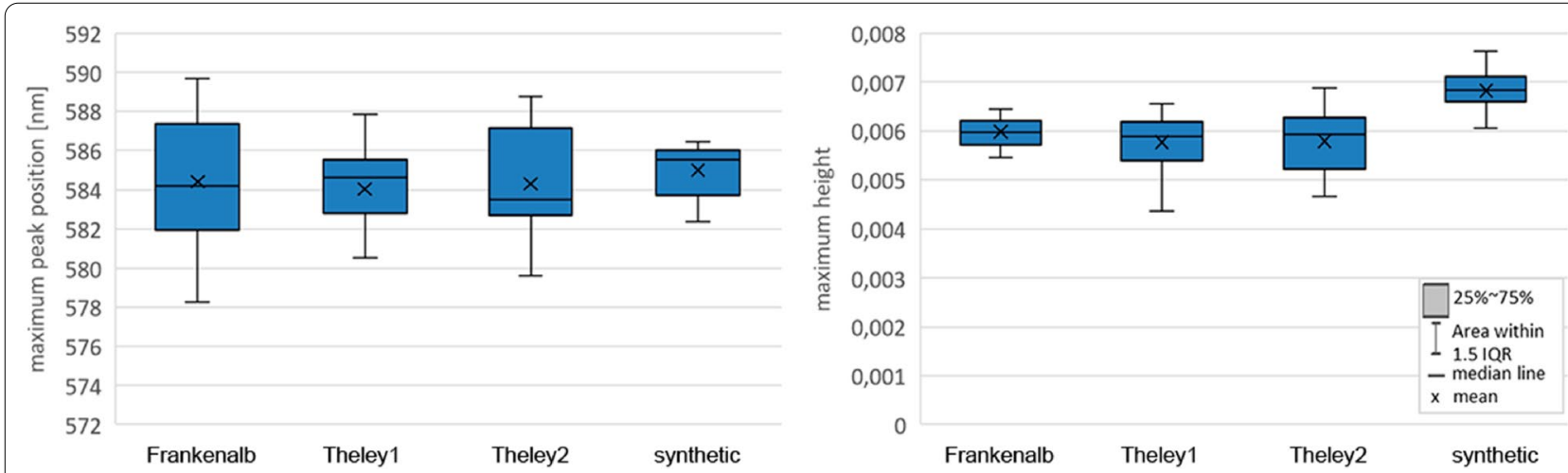

Fig. 8 Box plots of the red chalk types: distribution of the maximum peak positions of the first derivative (left); distribution of the maximum height of the first derivative (right). Box plot features the median line, mean values, and whiskers indicating 1.5 interquartile range (IQR)

FORS: spectral features of the red chalk drawing mock-ups The four chalk types (see Table 1) show slightly different spectral properties, influenced by their composition, application technique, and the paper support. First, the differences between the types of chalk were observed; for the sake of readability, here they are represented by the median spectra of the dry application on modern paper (Fig. 7). The curve shapes of the reflectance spectra of the red-chalk mock-ups differ most significantly at the start of the rise at $550 \mathrm{~nm}$, and with respect to the form of the slope of the rise between 600 and $750 \mathrm{~nm}$, as well as following the second rise, between ca. 760 and $950 \mathrm{~nm}$ (indicated by arrows).

The red chalk types could not be divided into groups solely based on the values for the maximum in the first derivate, even though trends were identified (Fig. 8; breakdown regarding application technique and chalk type, see Additional file 1: Fig. S3). The peak heights and positions for the natural chalks were found to be similar, and in general, they were more widely dispersed than 


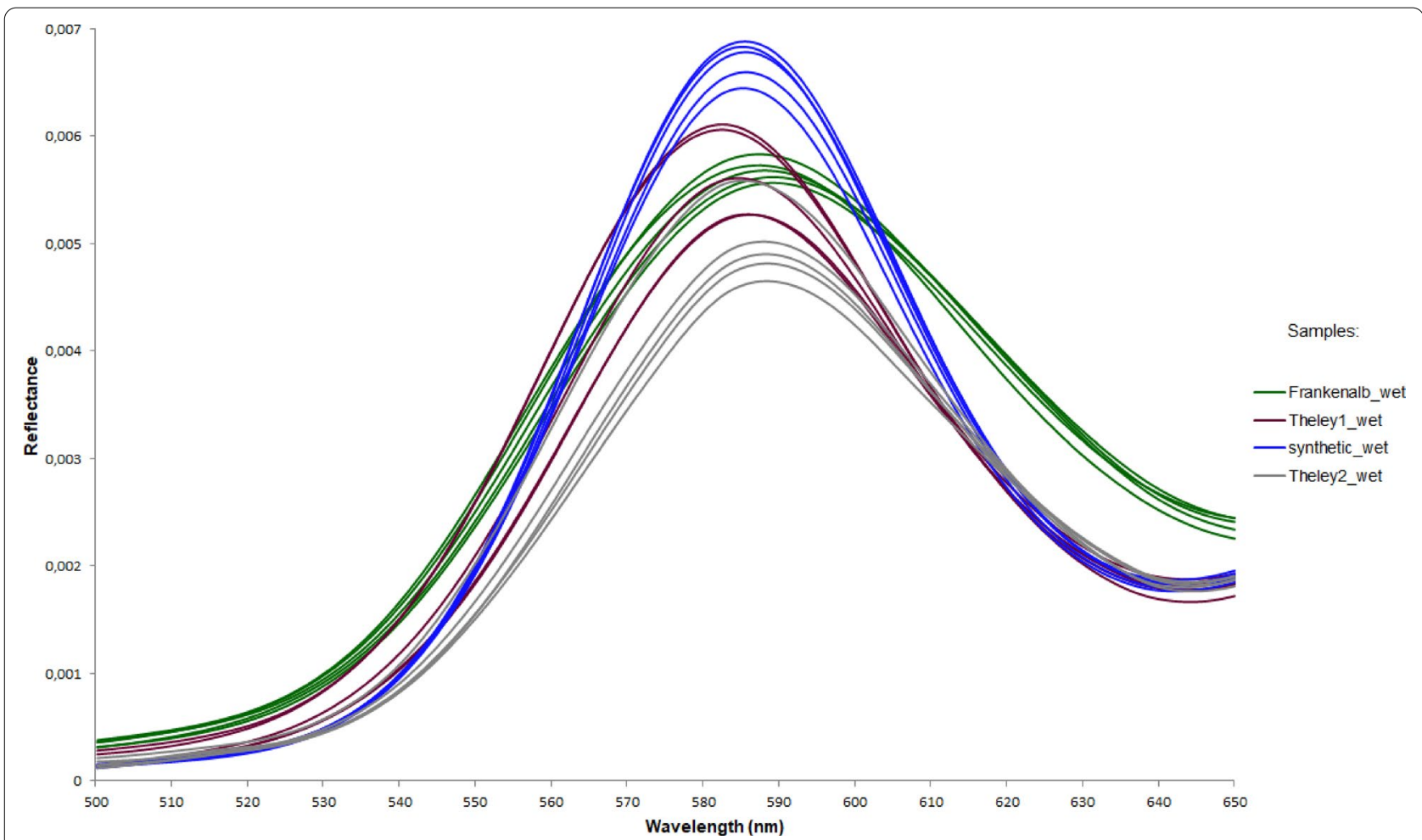

Fig. 9 First derivative of the FORS spectra between 500 and $650 \mathrm{~nm}$ for all chalk types (see Table 1) applied wet on modern paper

those of the synthetic chalks; the latter tend to display higher values with respect to these two points, with the smallest variation in the peak shift. The shift in the peak of the first derivative was overall quite small and occurred between 577 and $589 \mathrm{~nm}$. With our samples, there was no link between the hematite content and the position or the height of the maximum, as implied by studies using mixtures of synthetic sediments and very minor parts (up to 1\%) of hematite and goethite ([18] p 631). The shift induced by application technique was greater than that which was induced by compositional differences of the chalk type. In samples with a lower maximum, this maximum tends to move towards the higher wavelengths (see Additional file 1: Fig. S3). All of the wet and oiled chalk applications have lower peaks at higher wavelengths, whereas all of the dry and smudged applications have higher peaks at lower wavelengths. The synthetic red chalk with synthesized hematite was the only sample that displayed notably higher maximum readings. The production process of this chalk, optimized for color brightness and a more homogeneous product, assumedly could explain this.

The form of the first derivative of the spectra differed in accordance with the type of chalk and bundled sufficiently to facilitate their classification using PCA. The spectral curves could be best distinguished in the measurements taken from the smooth and dense applications of wet chalk strokes (Fig. 9; other applications, see Additional file 1: Figs S4b-d).

The shape of the spectral curves was also influenced by the chalk application technique (dry, smudged, wet, and oiled), as illustrated for the Theley1 measurements (Fig. 10; other chalks, see Additional file 1: Figs. S5b-d). Compared to the dry chalk strokes, the ones compacted by wetted or oiled application shifted the first slope rise towards higher wavelengths (see left arrow), and increased the absorption maximum in the near-infrared range (see right arrow). The spectra of the smudged chalks that featured more paper show-through displayed a steeper slope rise that started at lower wavelengths (ca. $610 \mathrm{~nm}$ ) and flattened out at $750 \mathrm{~nm}$ with a lower minimum in the subsequent higher area.

The paper type has an effect primarily on the dry and smudged red chalk samples, which can probably be attributed to the paper partially showing through the chalk. The blank modern paper features a higher reflectance in the low nm range than the blank historical paper, and a lower reflectance in the high nm range (Fig. 11). As can be expected, these trends influence the spectral curves of the dry chalk applied to the two papers. In the first derivative, the historical paper, in contrast to the 


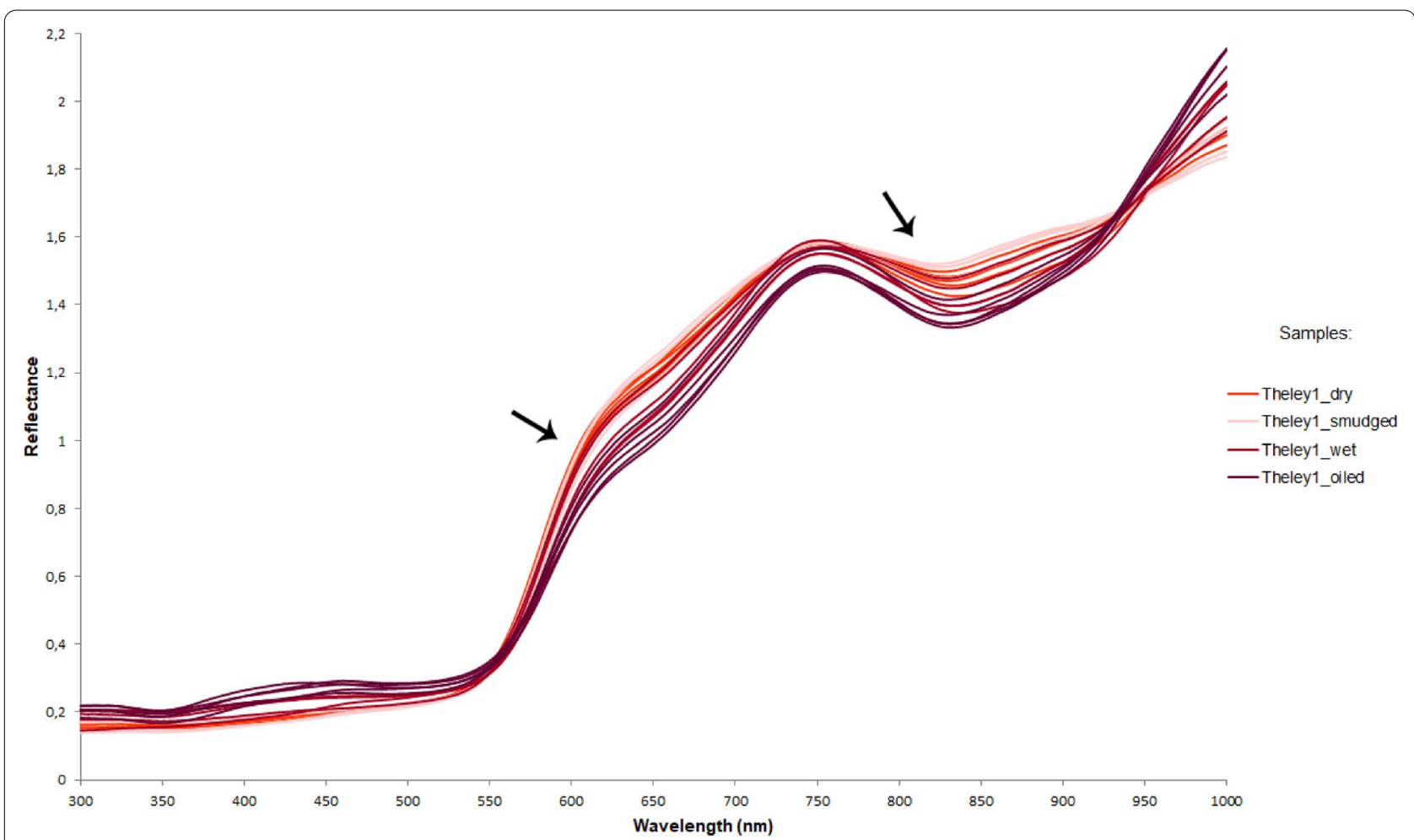

Fig. 10 FORS reflectance curves in dependence on chalk application technique (Theley1 on modern paper). Arrows mark areas affected by differences between application techniques

modern paper, tends to give rise to a lower peak with a shift at higher wavelengths in the dry application types.

\section{FORS: interpretation of FORS spectra on the basis of CIELAB}

The visual color perception of the red chalk mock-ups can be expressed in CIELAB values (Fig. 12).

Based on this system, it is possible to detect differences between the red chalk types. The Frankenalb chalk exhibits the highest overall L"a*b* values. They scatter less than the Theley chalks, which show the greatest variance and the lowest values for all three color properties of all the chalk types, caused by oiled and wet applications. The notable differences in hematite content cannot be seen expressed in the $\mathrm{a}^{*}$-values. As Barrón and Torrent studying hematite-deferrated soil mixtures have shown [37], this could be due to amounts of hematite close or above a saturation point (10\%), where only little fluctuation in color can be observed. However, the hematite-rich Theley samples exhibit readings with clearly lower $L^{*} \mathrm{a}^{*} \mathrm{~b}^{*}$-values than the other two samples and therefore appear darker and less saturated. It is notable that a higher content of non-tinting minerals is indicated by higher trending $L^{*}$-values for the Frankenalb and synthetic red chalks. It is possible that, at these high hematite concentrations, other factors (topography, particle shape) have stronger influence on the color appearance of red chalks than the hematite content. The synthetic chalk shows the least scattering which can be explained by its homogeneous composition (see 3.1 and 3.2). The greatest variation between the color values, however, can be explained by the different application techniques. Within each of the chalk types, the measuring points for the dry and smudged application techniques tend to have higher L*a*b* values than those for the wet and oiled applications.

\section{Principal component analysis of red chalk mock-ups}

For all chalk application techniques and paper types, PCA sorts the chalks into well-defined clusters in keeping with the chalk type (Fig. 13). Overall, three principal components explain $99 \%$ of the variance, whereby PC-1 explains 58\%, but PC-2 and PC-3, taken together, still explain a significant amount, namely $41 \%$ of the variance. The Theley 1 and Theley 2 chalks, which stem from the same geological area, make up one point cloud. The differences between these two and the two other chalk types are represented primarily in $\mathrm{PC}-2$ and $\mathrm{PC}-3$. The synthetic chalks showed more pronounced clustering 


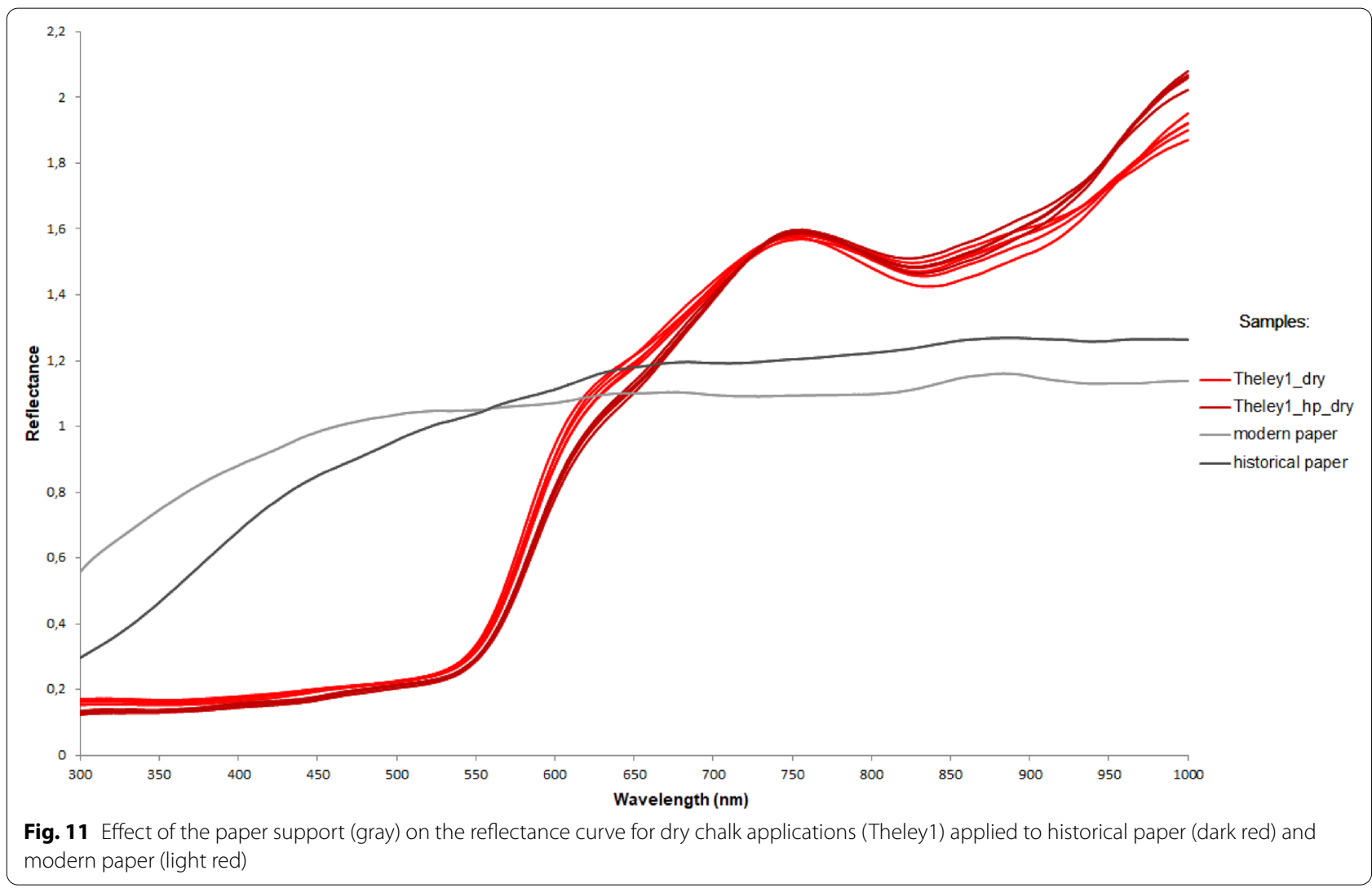

than the natural red chalks, indicating lower variance of surface topography within this red chalk type.

Within each group, the measuring points are dispersed in an elongated point cloud, sorted by the chalk application technique. The points spread along the axis of PC-1, which explains most of the variance. The dry chalk applications can, to an extent, be differentiated from the wet chalk applications. It is also possible to distinguish the applications on historical paper (the unfilled symbols) from the samples on modern paper.

The loadings plot (Fig. 14) was used to interpret the scores plot. It shows which wavelength ranges of the first derivative have an impact on the scores for each PC. In sum, PC-1 indicates differences in peak height (Additional file 1: Fig. S6), PC-2 differences in peak width and PC-3 differences in peak position (Additional file 1: Fig. S7).

For PC-1, the loadings plot, which followed the curve shape of the first derivative, showed that values around the maximum (at about $570 \mathrm{~nm}$ ) of the investigated wavelength range had the greatest impact: Samples with positive PC-1 scores in these areas had higher than average values. This value is directly related to the chalk application technique: For PC-1, the chalk strokes with rough surface (dry) or low coverage (smudged) showed the highest values, and the chalk applications that were compact and featured high coverage show the lowest values. Where the loadings plot for PC-1 showed a maximum, the loadings plot for PC-2 described a minimum in the negative region of the $y$-axis, slightly shifted toward the higher wavelengths (at $584 \mathrm{~nm}$ ). The loadings plot curve intersects the $\mathrm{x}$-axis at $564 \mathrm{~nm}$ and at $603 \mathrm{~nm}$. There are two maxima, one at $545 \mathrm{~nm}$, and one at $623 \mathrm{~nm}$, whereby the maximum in the higher wavelength range has a higher impact on the PC-2 scores than the lower one. The two maxima in the PC-2 loadings plot mark differences in the width of the first derivative's maxima of the samples. High impact loadings values in those ranges next to the actual maximum in the first derivative make it possible to describe the width of the curve, which was the important attribute for the determination of the chalk type in the analysis of the mock-ups. In the loadings plot for $\mathrm{PC}-3$, the maximum from the loadings plot for PC-1 describes the curve's point of inflection (at $578 \mathrm{~nm}$ ). The reflectance values before that point positively correlate with PC-3, with a maximum at $553 \mathrm{~nm}$, and the values after that point correlate negatively, with a minimum at $604 \mathrm{~nm}$. Thus, $\mathrm{PC}-3$ explains differences in the peak position. The higher the wavelength range of the maximum, the lower the value is for PC-3. Variances 


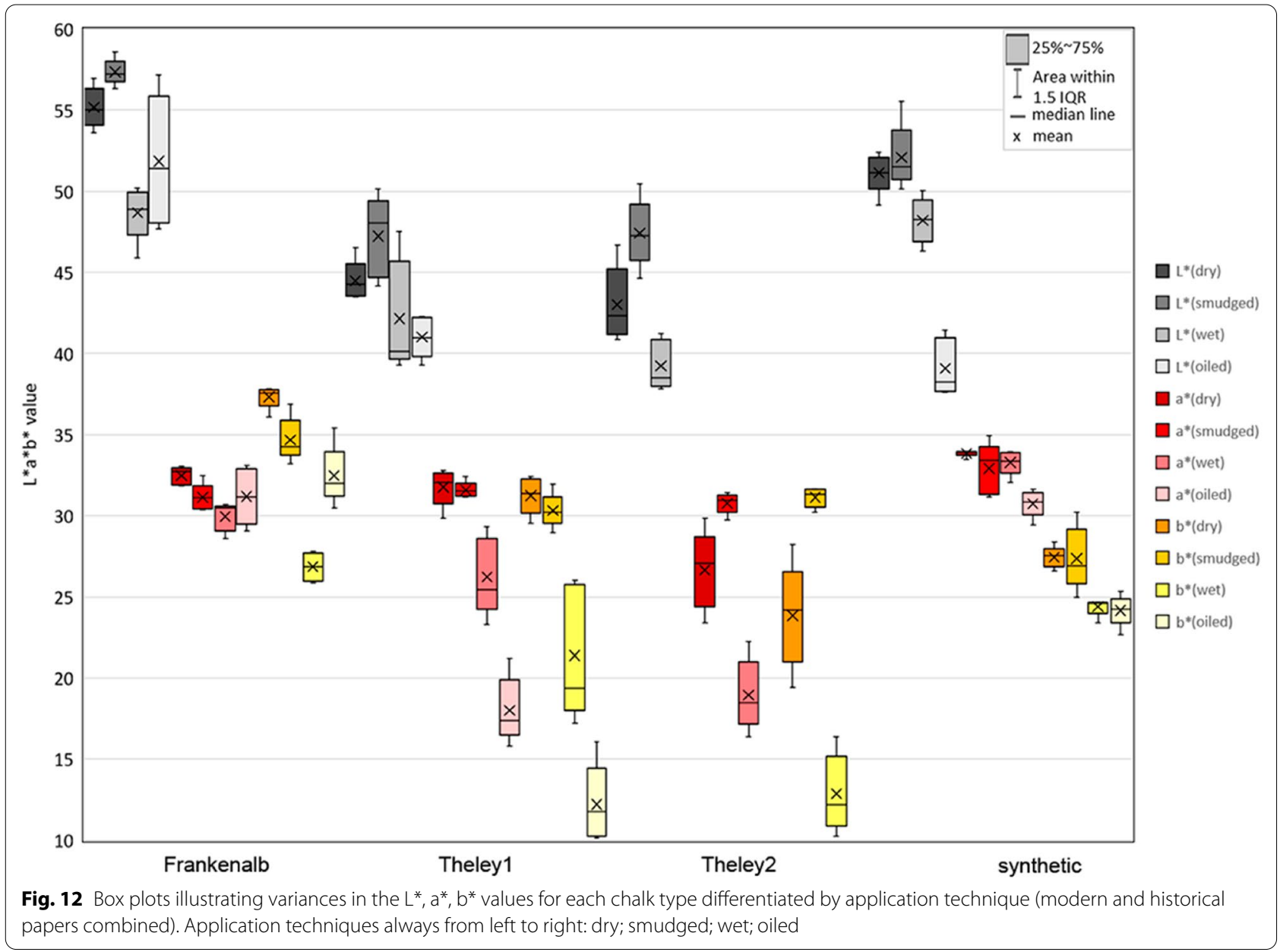

in the FORS spectra that could be visualized with PCA are also reflected in the CIELAB values. PC-1 correlates directly with the chromaticity values of the same measuring points and to a lesser degree with the lightness values: The higher the CIELAB values, the higher the PC- 1 values (Additional file 1: Fig. S8).

Since it was also possible to determine the impact of the application technique and paper type within a particular chalk, these factors were subjected to PCA analysis with the exclusion of other factors (that is to say, all of the application techniques for one chalk type on the same paper; or both paper types with the same application type and chalk type; or different types of chalk on the same paper type and with the same application technique). In all cases, $95 \%$ of the variance could be expressed with only two principal components, and often the share contributed by PC- 1 alone amounted to more than $90 \%$ of the variance. This implies that a sole factor accounts for most of the differences.

In most of the samples, it was possible using PCA to identify slight differences for a single chalk type on the basis of the application technique and the paper support. The differentiation of the application technique occurred primarily between dry and wet drawing techniques, in the positive and negative regions of PC-1 (Fig. 15, see also Additional file 1: Fig. S9). In three cases, groups formed loosely based on the chalk application technique. It was also possible to differentiate the paper type wherever their show-through was a contributing factor in the measurements; however, in two cases the effect falls within the differentiation axes of PC-2, with an explained variance of $9-18 \%$. It is thus possible for PCA to analyze differences in the application type or paper for a single red-chalk type and thereby cause "false positive" results.

\section{Differentiation of the red chalks in the Karlsruhe drawings}

FORS measurements of 79 red-chalk drawings were taken and analyzed using PCA to group them according to their spectral similarity. This allows to draw conclusions about the diversity of the red chalks used in the Piranesi workshop and in Rome. For drawings with more than 10 measured spectra, in each case the 10 spectra 


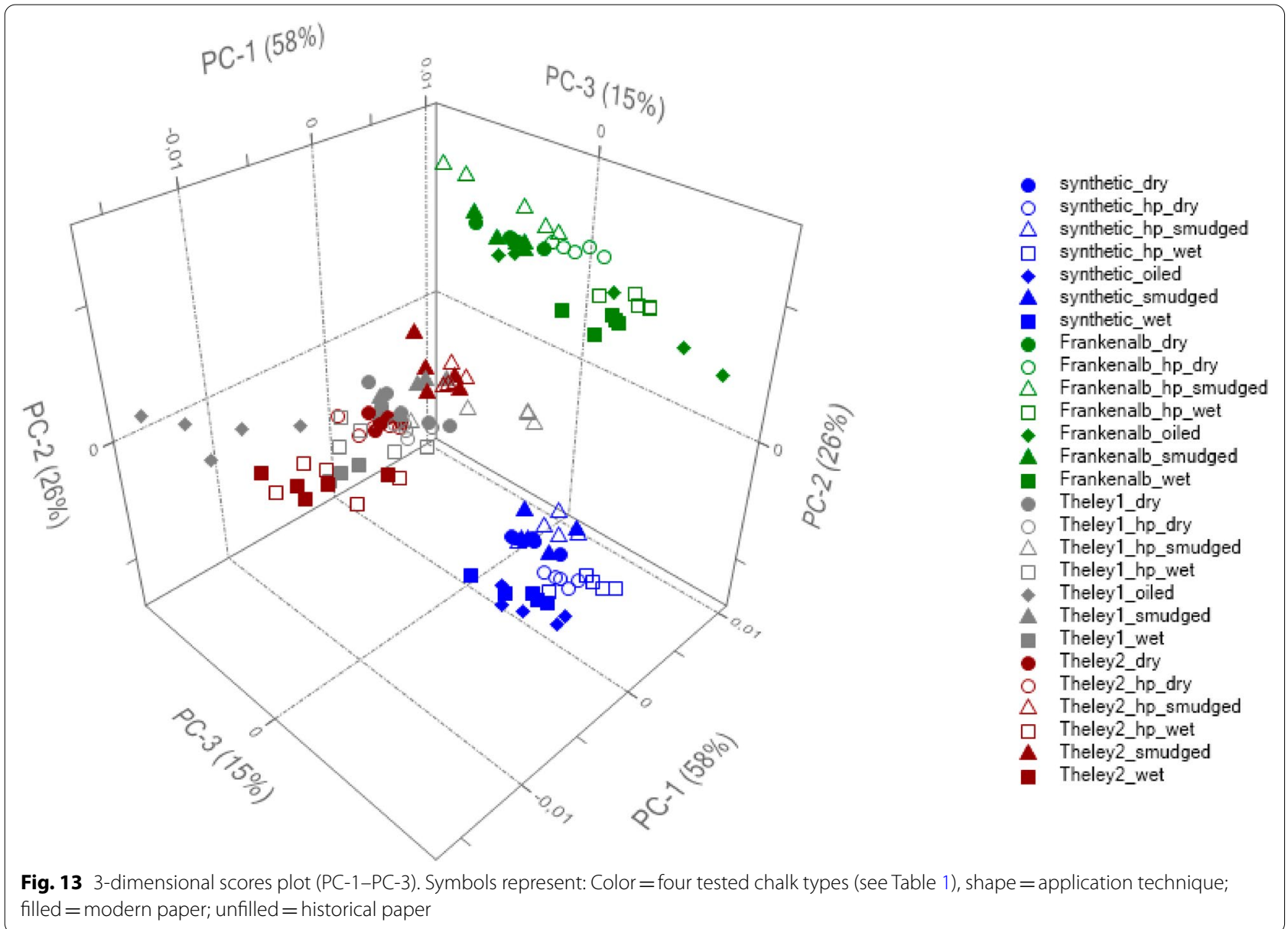

with maximum values closest to the median of the maximum values in the first derivative were used, to exclude outliers. In these cases, it was assumed that only one type of red chalk was used per drawing. For individual drawings, however, it should be considered that outliers might point toward different chalk types used within the same drawing.

The positions of the peaks in the first derivatives of the average spectra of the historic red-chalk samples were found between 571 and $589 \mathrm{~nm}$, and the height was between 0.00305 and 0.00658 (Fig. 16). The spectra of the historical samples resemble mostly those from Theley.

In the loadings plot, $\mathrm{PC}-1$ describes the peak height of the spectra in the first derivative, PC-2 correlates with the peak position, and $\mathrm{PC}-3$, which accounts for $6 \%$ of the variance, shows differences in the width of the curve, which is the main differentiating factor among the red chalks in the mock-ups (Fig. 17). Plotting the principal components with CIE L*a*b* values (Additional file 1: Fig. S10) supports this interpretation. PC-1 correlates with the $\mathrm{a}^{*}$ and $\mathrm{b}^{*}$ values of the historic drawings, i.e., red and yellow (Additional file 1: Fig. S11). The $\mathrm{L}^{*}$ value correlates with the peak position and tends to be projected onto PC-2 (Additional file 1: Fig. S12). A high PC-2 value indicates there is a particularly light color and that the position of the maximum is found in the lower wavelengths.

In the PCA score plot (Fig. 18a-c; 2D scatter plots see Additional file 1: Fig. S13d-f) the measuring points in the aggregate constitute a large, coherent point cloud, in which the respective drawings each take up clearly located and distinctly demarcated sub-spaces; individual drawings, however, exhibit more extensive scattering. The combined point cloud for all the drawings can be clearly differentiated from the clouds for the Frankenalb red chalk and the synthetic red chalk, but the measuring points of the aggregate cloud lie close to the elongated point cloud of the Theley chalks. The measuring points 


\section{Loadings PCA mock-ups}
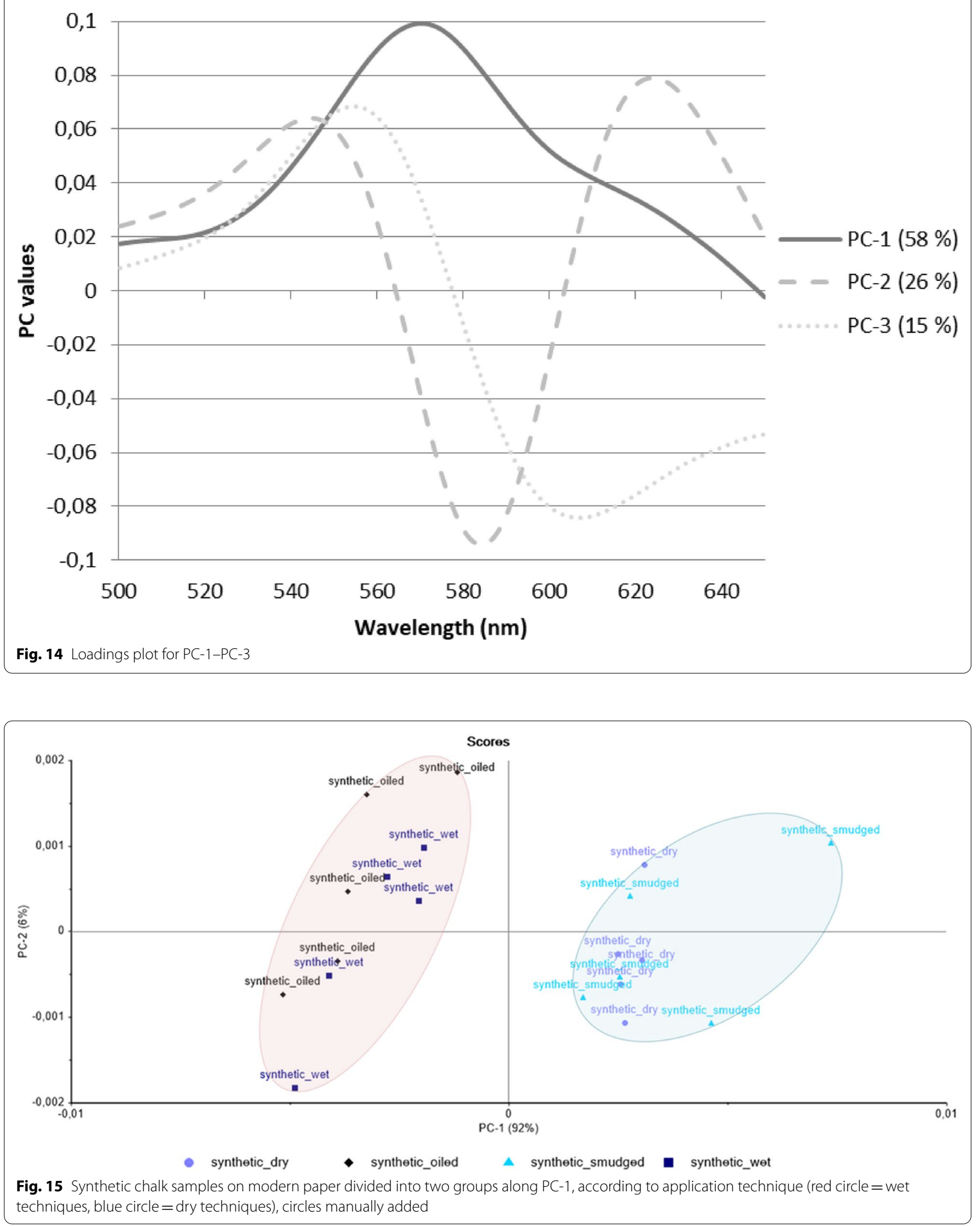


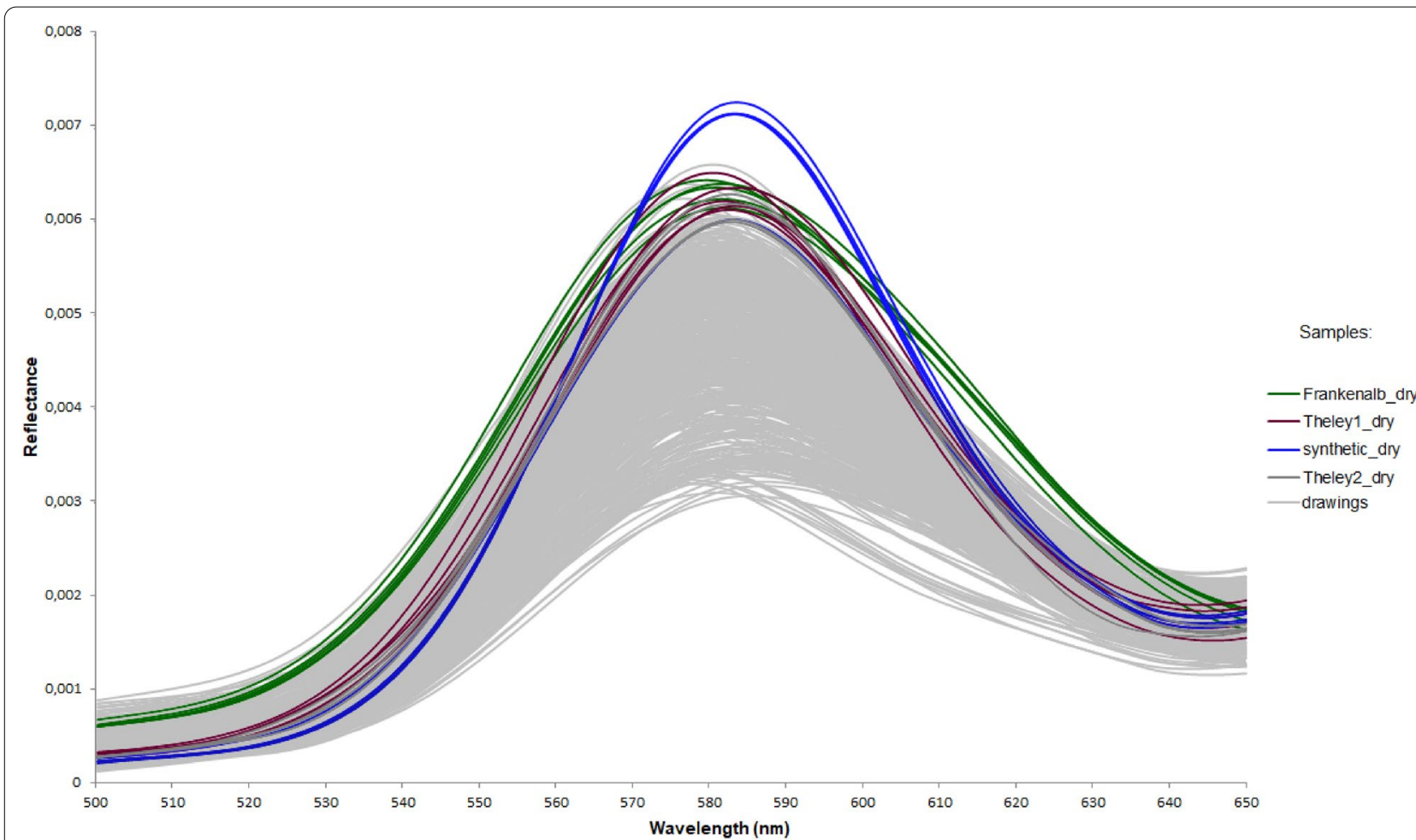

Fig. 16 Spectra (first derivative) of 79 original drawings (light gray) and multiple readings of the four reference chalk types (see Table 1) applied dry on modern paper

for the Frankenalb, Theley1 and Theley2 and FaberCastell chalks are concentrated in the positive region of $\mathrm{PC}-1$, and primarily in the negative region of PC-2. PC-3 is needed to separate the mock-ups into groups in regards to their chalk types. In an attempt to interpret the score plot based on the greatest overlaps; groups of samecolored symbols were assigned to the historical drawing measurements, which consisted of red-chalk drawings that were the most similar to each other. At the negative end of $\mathrm{PC}-1$, there is a clear overlapping of the measuring points from several drawings, which cluster and form a compact group (violet symbols). Set apart from this group, a second (beige symbols) forms, slightly offset toward the right on PC-1, and displaying a clear shift on $\mathrm{PC}-3$. Some of the drawings from these two groups could also be connected regarding their historical use and content, through the identification of several counterproofs that were made from them for architects visiting Rome, and which at present are attributed to the French draftsman Nicolas François-Daniel Lhuillier [1]. Counterproofing a freshly made drawing involved moistening it, which was advantageous because it fixed the remaining media on the paper, thereby prevented loss and smudging [7]. This facilitates the characterization of the chalks, as expressed in a lesser degree of data scattering, and a clear gap between their respective clusters. The red chalks that are not as easy to characterize are found in the center of the PC-1 scale. Their data points have a greater tendency to scatter, and they cannot be assigned to a compact overall group (symbols in pink, purple, green and other colors). Yellow symbols mark red-chalk drawings featuring a low coverage with paper show-through, which also scattered to a great degree toward PC-2. At the positive end of PC-1 of the point cloud of historical red chalk samples, a number of red chalks, in turn, clearly overlap each other (red symbols).

We chose selected original drawings (Fig. 19a) to show how differences in the reflectance spectra and the first derivative (Fig. 19b-c) impact the score plot. Red chalks with negative PC-1 values (beige and violet symbols) display a flatter spectrum with higher initial reflectance values (35-13-1 in Fig. 19b-c). The chalks on the positive end of PC-1 (in red) are characterized by the steeper rise of their spectra with lower initial reflectance values (35-10-2 in Fig. 19b-c). The chalks in the middle of PC-1 that have distinctly positive values for $\mathrm{PC}-2$ have a spectrum with a similarly steep slope, but markedly higher initial reflectance values. In the first derivative this feature is expressed as a high peak accompanied by a shift of the maximum into the lower wavelength regions; this 


\section{Loadings PCA drawings}

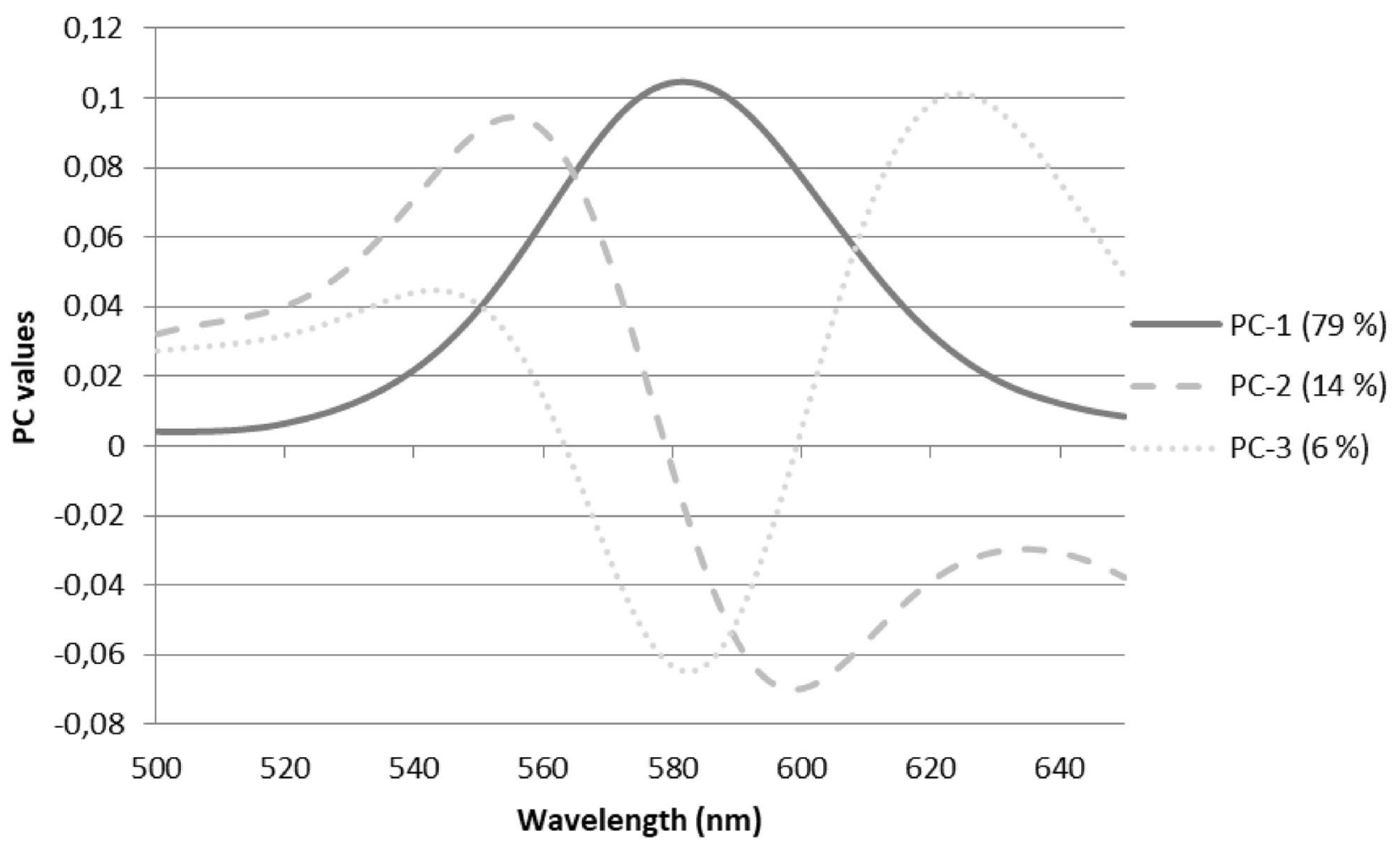

Fig. 17 Loadings plots for $P C-1-P C-3$ for the $P C A$ of the drawings

correlation was observed for the mock-ups, in connection with applications that featured lower coverage or smudging.

\section{Conclusion}

PCA enhances the comparison of spectral data of different substrates and clusters them accordingly. To interpret the PCA results, the specific factors that influence them need to be linked to the individual differences in the spectra. In this study, the interpretation of the red chalk spectra is based on known differences of the mock-up preparation (different chalk types, paper supports, and application techniques) and analysis of the mineral composition of the chalks studied.

Four different natural and synthetic red chalk reference samples could be differentiated based on their FORS spectra via PCA, which indicates the potential of FORS in the differentiation of red chalks on original drawings. We could show that chalk composition and the application technique on paper influence the VIS spectra. These variations are expressed through different spectral shapes and CIELAB color values. Via PCA, it is possible to visualize these differences based on a selected region
$(500-650 \mathrm{~nm})$ of the VIS spectrum in the first derivative. For the red chalk drawings of the Karlsruhe Piranesi albums, PC- 1 correlates with the CIE $\mathrm{a}^{*}$ and $\mathrm{b}^{*}$ values of the chalks, i.e., their redness and yellowness. The $L^{*}$ value correlates with the position of the maximum in the first derivative and tends to be expressed in $\mathrm{PC}-2$, thus a high $\mathrm{PC}-2$ value indicates a particularly light color.

FORS measurements of art on paper will be influenced by the unevenness of the paper support. In the context of required non-contact measurements on historic objects, this leads to a greater variance within the spectra. This should be compensated for with a multiplicative scattering correction. In addition, the degree of coverage within a red chalk line has an influence on the interpretation of the data. These factors can lead to ambiguities in the interpretation of the PCA, therefore a compositional analysis must accompany a study that seeks to differentiate between red chalk types. FORS in combination with PCA cannot provide information about the origin of a chalk since this information is reflected primarily in the colorless components of the chalk and its chemical composition, including trace elements. 


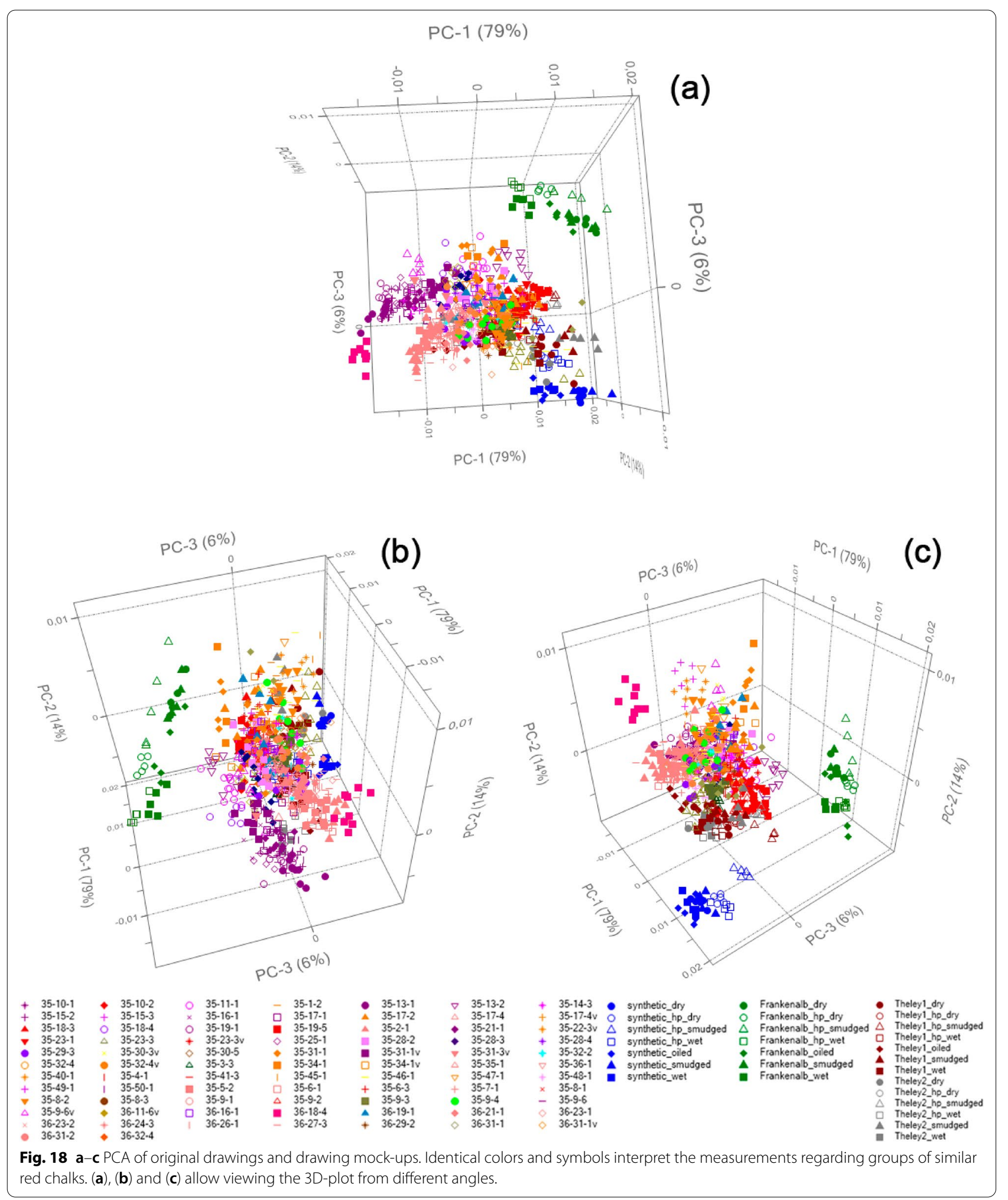




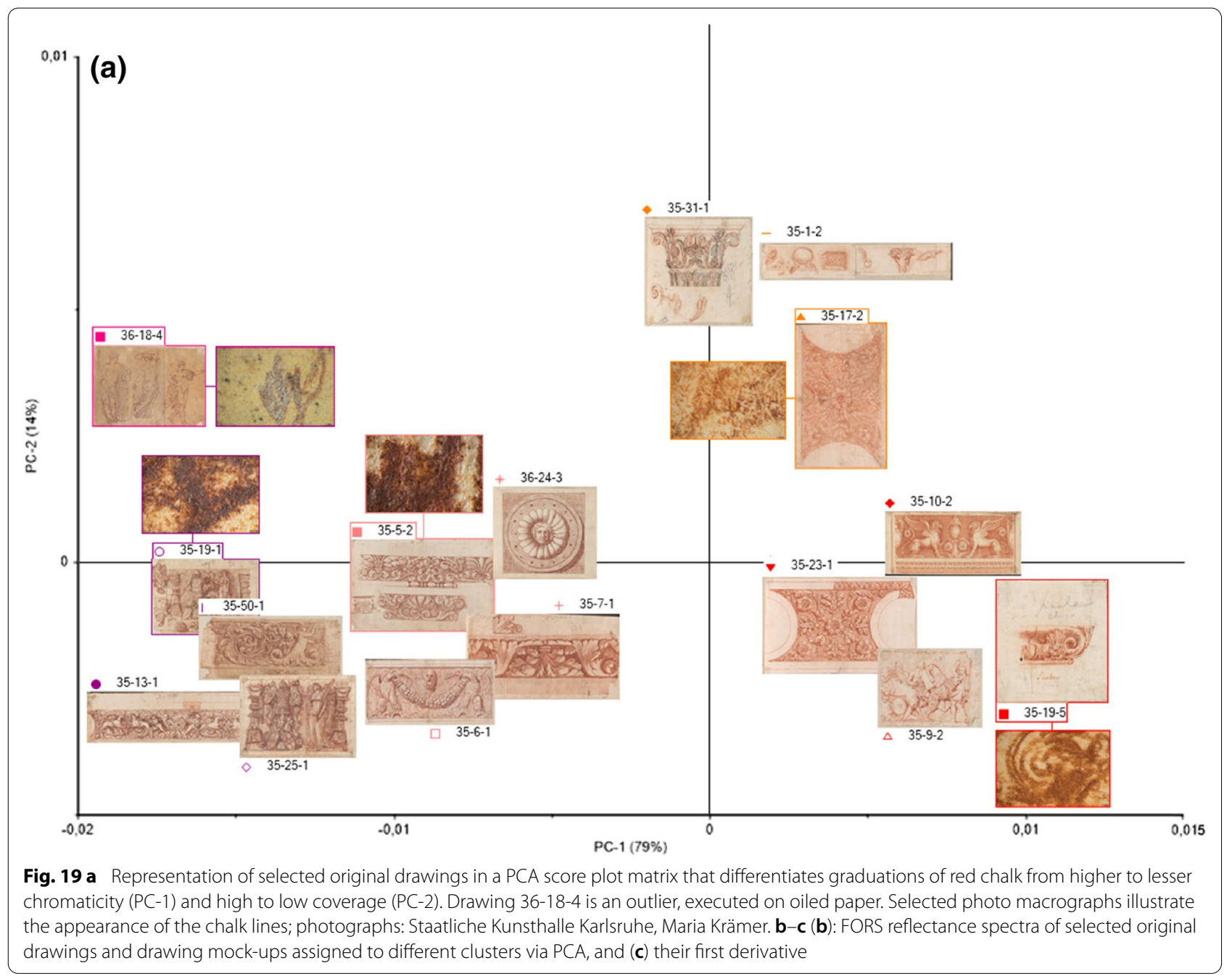

When this analytical concept was applied to a large group of red-chalk drawings from the Piranesi workshop, it was also possible to identify differences among the individual drawings. These, however, could not be clearly attributed to a single factor, e.g., hematite content. Despite these limitations of FORS in the study of red chalk as one single drawing medium, it was possible via PCA to divide up the historical red chalks that had a close temporal and spatial relationship to each other into several groups. The distances between the groups were considerably smaller than those between the original samples and the mock-up chalks, and all samples together were spread across a range in which two red chalk mock-ups from one geological region (Theley1 and 2) were represented.
By using a larger range of comparison spectra from known sample chalks, it may be possible to further refine the differentiation of the PCA. In combination with multivariate analysis, FORS can thus become a powerful tool for the contactless differentiation of single drawing media. Another question to be studied in this context could be the differentiation between synthetic and natural red chalks, for which promising approaches have been described in this paper. As the use of natural red chalk steadily declined during the nineteenth century with the production of synthetic hematite pigments (so-called "Mars Colors") ([10], p 178), combining FORS and PCA could also be helpful in the detection of forgeries. 


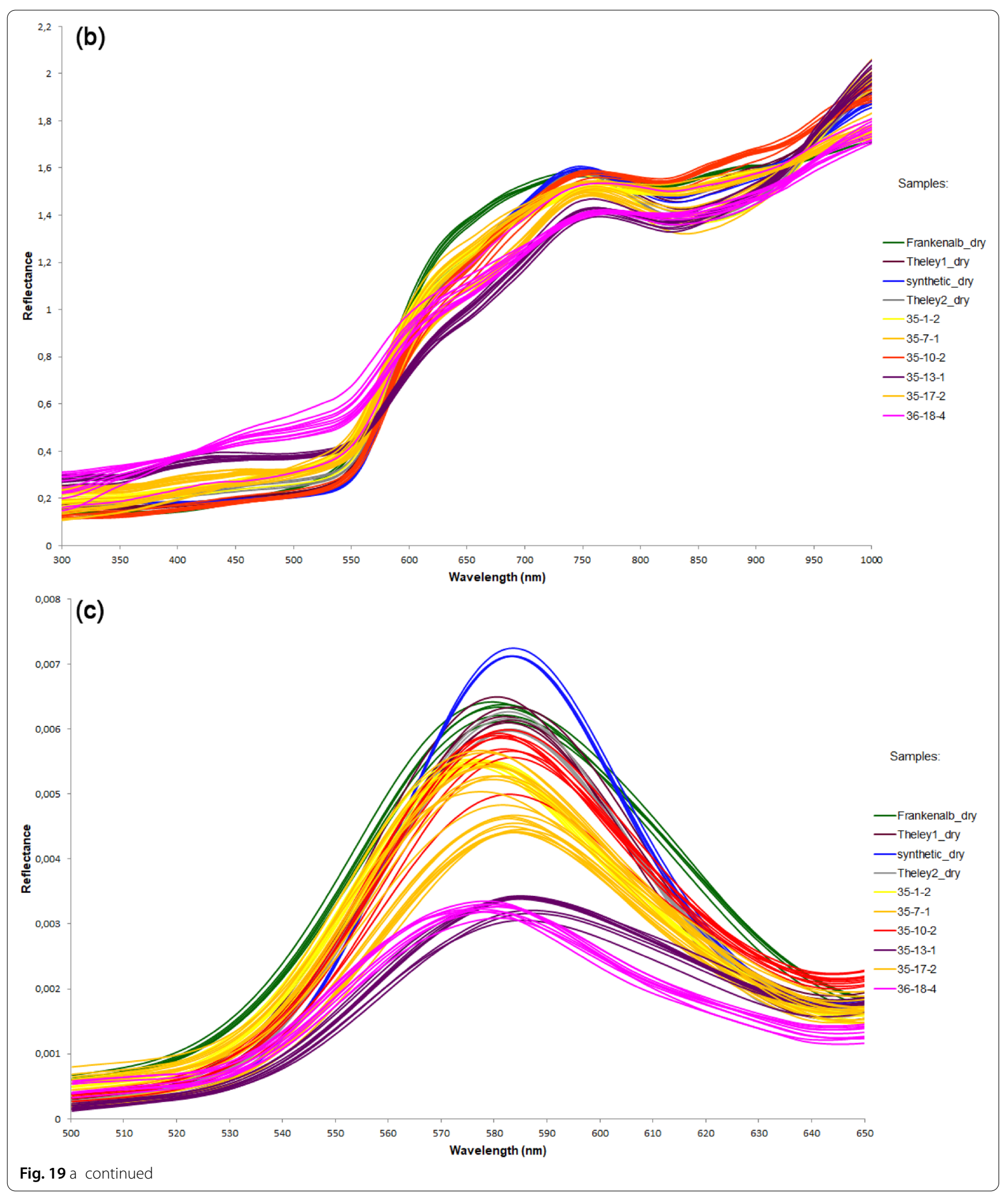




\begin{abstract}
Abbreviations
BE: Back-scattered electron; CIE: Commission Internationale de l'Éclairage (International Commission on Illumination); DFG: Deutsche Forschungsgemeinschaft (German Research Foundation); EDX: Energy-dispersive X-ray spectroscopy; FESEM: Field-emission scanning electron microscopy; FORS: Fiber optics reflectance spectroscopy; NIPALS: Nonlinear iterative partial least squares; PCA: Principal component analysis; SE: Secondary electron; SEM: Scanning electron microscope; SVD: Singular value decomposition; XRD: X-ray diffraction.
\end{abstract}

\section{Supplementary Information}

The online version contains supplementary material available at https://doi. org/10.1186/s40494-021-00578-1.

Additional file 1: Table S1. XRD-results of five red chalk specimens (after Mayhew et al. 2014, 103). Figure S2. XRD spectra. Figure S3. Box plots of the peak height and position of the first derivative within a single chalk type. The lower peaks tend to be found more often in higher-wavelength regions than higher peaks are. Figure S4b-d. 1st derivative 500-650 nm of red chalks on modern paper sorted by application technique: (b) dry (c) smudged (d) oiled. Figure S5b-d Effect of the application technique on the reflectance curve for the chalk samples on modern paper: (b) Frankenalb, (c) Theley2, (d) synthetic. Figure S6. The maxima of the first derivative spectra of the mock-ups correlate to PC-1, as also expressed in the loadings plot. Figure S7. Peak positions of the first derivative spectra of the mock-ups correlate negatively to PC-3. Figure $\mathbf{S 8}$. Correlation of $L^{*}$, $a^{*}$, and $b^{*}$ values of the mock-ups to PC-1. Figure $\mathbf{S 9} b-d$. Scores plot for the different application techniques for each chalk type on modern paper: (b)Frankenalb (c) Theley1 (d) Theley2. Figure S10. Scatter plot of the CIE $L^{*} a^{*} b^{*}$ values of original drawings and drawing mock-ups combined. Identical colors and symbols interpret the measurements with regard to groups of similar red chalks. Figure S11. Correlation of PC-1 with CIE $a^{*}$ and $b^{*}$ values of original drawings and drawing mock-ups. Figure $\mathbf{S 1 2}$. Weak correlation of CIE L* values with PC-2. Fig. S13d-f. 2D scatter plots of the PCA of original drawings and drawing mock-ups. Identical colors and symbols interpret the measurements with regard to groups of similar red chalks.

\section{Authors' information}

Maria Krämer currently pursues her doctorate at the Stuttgart State Academy of Art and Design in Stuttgart (Germany), where she received her M.A. in paper conservation in 2015 at the study program Conservation of Works of Art on Paper, Archives and Library Materials. Following work as a freelanceconservator, she became member of the interdisciplinary research team at the Staatliche Kunsthalle Karlsruhe in 2017, where she presently investigates the drawings of the 18th-century Italian architect, designer, and printmaker Giovanni Battista Piranesi and his workshop, focusing on the artists' materials and methods. She has published on red chalk drawings and conservation treatments including bleaching. This paper is part of her doctorate work. Ute Henniges received a doctorate in 2008 from the University of Natural Resources and Life Sciences, Vienna (BOKU), and is a trained paper conservator. From 1999-2003, she studied paper conservation at the Stuttgart study program (see Krämer). From 2003 to 2005 she was employed at PAL Preservation Academy GmbH Leipzig as a paper conservator. From 2008 to 2018, she worked as a researcher in paper conservation-related topics at the Department of Chemistry, University ofNatural Resources and Life Sciences, Vienna (BOKU) where she also obtained a post-doctoral degree. Since 2018, she is academic staff member at the Stuttgart study program. Irene Brückle is professor and director of the Stuttgart study program (see Krämer) since 2008. Between 1988 and 1990, she worked grant-funded at different American Museums. From 1990 to 2004, she taught at the Art Conservation
Department, Buffalo State College and became professor there in 1992. She holds an M.A. in art history from the University at Buffalo and a doctorate from the Stuttgart State Academy. From 2005 to 2008, she was head of conservation at the Kupferstichkabinett, Staatliche Museen zu Berlin. She received the Caroline Keck award for excellence in teaching in 2006 from the American Institute for Conservation. She is member of Piranesi project leading team. Laura Lenfant is a M. Sc. student at Karlsruhe Institute of Technology (KIT) in Applied Geosciences with focus on mineralogy and geochemistry. Red chalk is the research subject of her master's thesis. Kirsten Drüppel is an adjunct professor for mineralogy and petrology at the Karlsruhe Institute of Technology (KIT). After she had received her PhD at Würzburg University (2003), she taught at the Technical University, Berlin (2004-2010) and held a position as substitute chair at the Free University, Berlin (2010-2011). Since 2011 she has been working at KIT. Her research and publication interests mainly include field-related petrological studies in Greece, Norway, Turkey/Syria, and Namibia, fluid-rock interaction, and archaeometry.

\section{Acknowledgements}

The DFG is gratefully acknowledged for making this research possible. We also thank Tiziana Cavaleri at the Fondazione Centro Conservazione e Restauro "La Venaria Reale" Turin for valuable information on the practice of FORS, computation and interpretation of data, and for supporting measurements. Her input in the initial phase of the project was vital in setting us on the path that led to this paper. We also would like to thank Dorit Schäfer at the Kunsthalle Karlsruhe for her instrumental and continued support in the Piranesi research project. We thank Johannes Gfeller, director of the study program New Media and Digital Technology at the Stuttgart State Academy, who engineered and built the FORS measuring frame and Natascha Wichmann for initial testing of FORS with the custom-built system as part of student projects at the Stuttgart State Academy (see Krämer).

\section{Authors' contributions}

MK was responsible for the conception of the study. She carried out the FORS analysis, was responsible for the realization and interpretation of the PCA, and for drafting and revising the manuscript. UH suggested PCA and supported the analysis, the spectral data interpretation and management, as well as editing the manuscript. LL and KD provided the SEM and SEM-EDX analyses and data interpretation, carried out the XRD analysis, and provided mineral modes and interpretation of the mineralogical data. Critical editing of the manuscript was provided by IB and UH. All authors read and approved the final manuscript.

\section{Funding}

Open Access funding enabled and organized by Projekt DEAL. The project "Giovanni Battista Piranesi and his workshop: Two Newly Identified Albums in Karlsruhe", to which this research contributes, is funded by the German Research Foundation and the Swiss National Science Foundation (DFG, project number 323516160; https://gepris.dfg.de/gepris/projekt/323516160 and SNSF project numbers 170303 and 185525; http://p3.snf.ch/project-170303 and http://p3.snf.ch/project-185525, accessed 18 August 2021).

\section{Availability of data and materials}

The datasets analyzed during the current study are available from the corresponding author upon reasonable request.

\section{Declarations}

Competing interests

The authors declare that they have no competing interests.

\section{Author details}

${ }^{1}$ Stuttgart State Academy of Art and Design, Stuttgart, Germany. ${ }^{2}$ Staatliche Kunsthalle Karlsruhe, Karlsruhe, Germany. Institute of Applied Geosciences of the Karlsruhe Institute of Technology (KIT), Karlsruhe, Germany.

Received: 31 May 2021 Accepted: 19 Auqust 2021

Published online: 15 September 2021 


\section{References}

1. Kabierske G. A cache of newly identified drawings by Piranesi and his studio at the Staatliche Kunsthalle Karlsruhe. Master Drawings. 2015;53:147-78

2. Kabierske G. Weinbrenner und Piranesi. Zur Neubewertung von zwei Grafikalben aus dem Besitz Friedrich Weinbrenners in der Staatlichen Kunsthalle Karlsruhe. In: Kleinmanns J, Baumstark B, editors. Friedrich Weinbrenner 1766-1826, Architektur und Städtebau des Klassizismus. Petersberg: Imhof; 2015. p. 75-87.

3. Kabierske G. Vasi, urne, cinerarie, altari e candelabra: newly identified drawings for Piranesi's antiquities and sculptural compositions at the Staatliche Kunsthalle Karlsruhe. In: Nevola F, editor. Giovanni Battista Piranesi. Predecessori, contemporanei e successori: studi in onore di John Wilton-Ely. (=Studi sul Settecento romano, vol. 32). Rome: Edizioni Quasar; 2016. p. 245-262.

4. Meder J. Die Handzeichnung -ihre Technik und Entwicklung (2nd edition). Wien: Scholl\&Co; 1923.

5. Mayhew TD, Hernandez S, Anderson PL, Seraphin S. Natural red chalk in traditional old master drawings. JAIC. 2014;53(2):89-115.

6. Roland Michel M. Sanguines: dessins français du dix-huitième siècle. Paris: Galerie Cailleux; 1978

7. Glück E, Krämer M. Chodowieckis Rötelzeichnungen für das plastische Bildprogramm des Französischen Doms in Berlin-Kunsttechnologie und Restaurierung. In: Schultz A, editor. Turmbewohner. Entwurfszeichnungen von Chodowiecki und Rode für den Gendarmenmarkt. Berlin: Akademie der Künste; 2014. p. 71-87

8. Elias M, Chartier C, Prévot G, Garay H, Vignaud C. The colour of ochres explained by their composition. Mater Sci Eng, B. 2006;127(1):70-80. https://doi.org/10.1016/j.mseb.2005.09.061.

9. Reissland B. Puur natuur. Rood tekenkrijt in de geschiedenis. Tijdschrift van de Rijksdienst voor het Cultureel Erfgoed. 2019:2:28-30.

10. Mayer DD, Vandiver P. Red chalk: historical and technical perspectives. Part 2: a technical study. In: Strauss W, editor. Drawings defined. New York: Abaris Books; 1987. p. 171-180; Suppl p. 432

11. Hund F. Inorganic pigments: basis for coloured, uncoloured and transparent properties. Angew Chem Int Ed Eng. 1981;20:723-30.

12. Cornell RM, Schwertmann U. The iron oxides: structure, properties, reactions occurrences and uses. 2nd ed. Weinheim: Wiley-VCH; 2003.

13. Schwertmann U. Relations between iron oxides, soil color, and soil formation. In: Bigham JM, Ciolkosz EJ, editors. Soil color. Vol. 31. 1993. p. 51-69. https://doi.org/10.2136/sssaspecpub31.c4.

14. Kerker M, Scheiner P, Cooke DD, Kratohovil JP. Absorbance index and colour of colloidal hematite. J Colloid Interface Sci. 1979;71:176-87.

15. Reinhold CL. Die Zeichen- und Mahlerschule. Münster, Osnabrück: Phillip Heinrich Perrenon; 1786.

16. Church AH. The chemistry of paints and paintings. London: Seeley, Service \& Co. limited; 1915.

17. Dubiel S, Cieslak J, Tarasiuk J, Niziol J. Relationship between colours of ochre from Roussillon and content of iron-bearing minerals. Appl Clay Sci. 2011;51(1-2):54-60. https://doi.org/10.1016/j.clay.2010.11.001

18. Deaton BC, Balsan WL. Visible spectroscopy. A rapid method for determining hematite and goethite concentration in geological materials. J Sediment Petrol. 1991;61:628-32.

19. Fernandez RN, Schulze DG. Munsell colors of soils simulated by mixtures of goethite and hematite with kaolinite. Z Pflanzenernährung Bodenkunde. 1992;155:473-8. https://doi.org/10.1002/jpln.19921550520.

20. Scheinost A, Chavernas A, Barrón V, Torrent J. Use and limitations of second-derivative diffuse reflectance spectroscopy in the visible to nearinfrared range to identify and quantify Fe oxides in soils. Clays Clay Miner. 1998:46:528-36. https://doi.org/10.1346/CCMN.1998.0460506.

21. Scheinost A, Schulze D, Schwertmann U. Diffuse reflectance spectra of Al substituted goethite: a ligand field approach. Clays Clay Miner. 1999:47:156-64. https://doi.org/10.1346/CCMN.1999.0470205.

22. Huguenin $\mathrm{RL}$, Jones $\mathrm{JL}$. Intelligent information extraction from reflectance spectra: absorption band positions. J Geophys Res. 1986;91:9585-98.

23. Sherman DM, Waite TD. Electronic spectra of $\mathrm{Fe}^{3+}$ oxides and oxide hydroxides in the near IR to near UV. Am Miner. 1985;70(11-12):1262-9.

24. Bacci M, Baldini F, Carlà R, Linari R. A color analysis of the Brancacci Chapel Frescoes. Appl Spectrosc. 1991;45(1):26-31. https://doi.org/10.1366/ 0003702914337713
25. Dupuis G, Elias M, Simonot L. Pigment identification by fiber-optics diffuse reflectance spectroscopy. Appl Spectrosc. 2002;56(10):1329-36. https://doi.org/10.1366/000370202760354803.

26. Aceto M, Agostino A, Fenoglio G, Idone A, Gulmini M, Marcello P, Ricciardi $P$, Delaney JK. Characterisation of colourants on illuminated manuscripts by portable fibre optic UV-visible-NIR reflectance spectrophotometry. Anal Methods. 2014:6:1488-500. https://doi.org/10.1039/C3AY41904E.

27. Delaney JK, Ricciardi P, Deming Glinsman L, Facini M, Thoury M, Palmer $\mathrm{M}$, de la Rie ER. Use of imaging spectroscopy, fiber optic reflectance spectroscopy, and X-ray fluorescence to map and identify pigments in illuminated manuscripts. Stud Conserv. 2014;59(2):91-101. https://doi. org/10.1179/2047058412Y.0000000078.

28. Mounier, A, Le Bourdon, G, Aupetit, C, Belin C, Servant L, Lazare S, Lefrais Y, Daniel F. Hyperspectral imaging, spectrofluorimetry, FORS and XRF for the non-invasive study of medieval miniatures materials. Heritage Sci. 2014;2(24). https://doi.org/10.1186/s40494-014-0024-z.

29. Kogou S, Lucian A, Bellesia S, Bellesia S, Burgio L, Bailey K, Brooks C, Liang $\mathrm{H}$. A holistic multimodal approach to the non-invasive analysis of watercolour paintings. Appl Phys A. 2015;121:999-1014. https://doi.org/ 10.1007/s00339-015-9425-4

30. Aceto M, Agostino A, Fenoglio G, Picollo M. Non-invasive differentiation between natural and synthetic ultramarine blue pigments by means of 250-900 nm FORS analysis. Anal Methods. 2013;5(16):4184-9. https://doi. org/10.1039/C3AY40583D.

31. Daly NS, Sullivan M, Lee L, Delaney JK, Trentelman K. Odilon Redon's noir drawings: characterization of materials and methods using noninvasive imaging and spectroscopies. Herit Sci. 2019;7(43). https://doi.org/10. 1186/s40494-019-0286-6

32. Sharma V, Kumar R, Devgan K, Mishra P, Ekielski A, Kumar V, Kumar V. Multivariate analysis for forensic characterization, discrimination, and classification of marker pen inks. Spectrosc Lett. 2018;51(5):205-15. https:// doi.org/10.1080/00387010.2018.1452265.

33. Savitzky A, Golay MJE. Smoothing and differentiation of data by simplified least squares procedures. Anal Chem. 1964;36:1627-39. https://doi. org/10.1021/ac60214a047.

34. Jackson JE. A user's guide to principal components. New Jersey: John Wiley \& Sons; 1991

35. Vidal R, Ma Y, Sastry SS. Generalized principal component analysis. Interdisciplinary applied mathematics 40. New York: Springer; 2016.

36. Simonot L, Elias M. Color change due to surface state modification. Color Res Appl. 2003;28:45-9. https://doi.org/10.1002/col.10113.

37. Barrón V, Torrent J. Use of the Kubelka-Munk theory to study the influence of iron oxides on soil colour. J Soil Sci. 1986;37:499-510. https://doi. org/10.1111/j.1365-2389.1986.tb00382.x.

\section{Publisher's Note}

Springer Nature remains neutral with regard to jurisdictional claims in published maps and institutional affiliations.

\section{Submit your manuscript to a SpringerOpen ${ }^{\circ}$ journal and benefit from:}

- Convenient online submission

- Rigorous peer review

- Open access: articles freely available online

- High visibility within the field

Retaining the copyright to your article

Submit your next manuscript at springeropen.com 